\title{
A Numerical Taxonomic Study of Actinobacillus, Pasteurella and Yersinia
}

\author{
By P. H. A. SNEATH ${ }^{1}$ AND M. STEVENS $2 *$ \\ ${ }^{1}$ Department of Microbiology, Leicester University, Leicester LEI 7RH, UK \\ 2 Public Health Laboratory, Leicester Royal Infirmary, Leicester LEI $5 \mathrm{WW}$, UK
}

(Received 22 January 1985)

\begin{abstract}
A numerical taxonomic study of strains of Actinobacillus, Pasteurella and Yersinia, with some allied bacteria, showed 23 reasonably distinct groups. These fell into three major areas. Area A contained species of Actinobacillus and Pasteurella: A. suis, A. equuli, A. lignieresii, $P$. haemolytica biovar A, $P$. haemolytica biovar T, $P$. multocida, A. actinomycetemcomitans, 'P. bettii', 'A. seminis', P. ureae and P. aerogenes. Also included in A was a composite group of Pasteurella pneumotropica and $P$. gallinarum, together with unnamed groups referred to as 'BLG', 'Mair', 'Ross' and 'aer-2'. Area B contained species of Yersinia: $Y$. enterocolitica, $Y$. pseudotuberculosis, $Y$. pestis and a group 'ent-b' similar to $Y$. enterocolitica. Area $C$ contained non-fermenting strains: Y. philomiragia, Moraxella anatipestifer and a miscellaneous group 'pastb'. There were also a small number of unnamed single strains.
\end{abstract}

\section{INTRODUCTION}

The genera Actinobacillus and Pasteurella are very similar, and are closely related to Haemophilus. Together they form the HPA group (recently reviewed in Kilian et al., 1981). We here present findings on Actinobacillus and Pasteurella to extend earlier work on Haemophilus (Broom \& Sneath, 1981) and we have included some data on Yersinia, which has historically been considered an allied group. Names that are not validly published [because they are not included in the Approved Lists of Bacterial Names (Skerman et al. 1980) or have not been validly published since then] are placed in inverted commas.

\section{METHODS}

Strains. These are listed in Table 1. Strains were checked for purity and stored as suspensions in basal medium broth containing $15^{\circ}{ }_{0}(\mathrm{v} / \mathrm{v})$ glycerol on beads at $-76^{\circ} \mathrm{C}$ (Feltham et al., 1978). Working cultures were maintained on Blood Agar Base No. 2 (Difco).

Basal media. Basal medium broth (BMB) contained $\left(\mathrm{l}^{-1}\right)$ : proteose peptone (Difico), $15 \mathrm{~g} ; \mathrm{NaCl}, 5 \mathrm{~g}$; yeast extract (Difco). $5 \mathrm{~g}$ : and liver digest (Oxoid). $2.5 \mathrm{~g}$. Basal medium agar (BMA) was Blood Agar Base No. 2 (Difco).

Standard culture conditions. Except when stated otherwise all cultures were incubated at $37 \mathrm{C}$ aerobically. The standard inoculum was one loopful of a $16 \mathrm{~h} \mathrm{BMB}$ culture diluted to give the same turbidity as tube no. 2 on the McFarland scale. Tests were read after $2 \mathrm{~d}$ unless otherwise stated, but API galleries were read after $24 \mathrm{~h}$.

Colonial and cellular morphology. Strains grown on BMA with horse blood $\left(7^{\circ}, \mathrm{v}, \mathrm{v}\right)$ for $24 \mathrm{~h}$ were examined for colonial features and slimy colonies recorded. Haemolysis of sheep blood $\left(7^{\circ}, v / v\right)$ in BMA was recorded after 24 and $48 \mathrm{~h}$ as greening. complete haemolysis, or no haemolysis. Heat-fixed films of $24 \mathrm{~h}$ horse blood BMA cultures were stained by Gram's stain (Cowan, 1974), and sizes measured with an eyepiece micrometer. The depth of staining, presence of mucus and extent of bipolar staining were recorded. Motility was examined in hanging drops from $24 \mathrm{~h}$ cultures in $\mathrm{BMB}$ at $35^{\circ} \mathrm{C}$, and from $48 \mathrm{~h}$ cultures in $\mathrm{BMB}$ containing $0 \cdot 25^{\circ}{ }_{0}(\mathrm{w} / \mathrm{v})$ agar at $25^{\circ} \mathrm{C}$ and $35 \mathrm{C}$.

Growth at different temperatures and resistance to heat. Strains were grown in divided dishes (Replidishes; Sterilin) on BMA, and visible growth was recorded after $2 \mathrm{~d}$ at $4{ }^{\circ} \mathrm{C}, 10^{\circ} \mathrm{C}, 15^{\circ} \mathrm{C}$ and $45^{\circ} \mathrm{C}$. Resistance to heat was

Ahbretiations: BMA, basal medium agar; BMB, basal medium broth; ONPG, $\alpha$-nitrophenyl $\beta$-Dgalactopyranoside; OTU, operational taxonomic unit. 
Table 1. Strains studied and their clustering (using the $S_{G}$ coefficient) in the same order as Fig. 1

\begin{tabular}{|c|c|}
\hline $\begin{array}{c}\text { Strain } \\
\text { no. }\end{array}$ & Name as received \\
\hline Phenon 1: & Actinobacillus suis \\
\hline Al & A. suis \\
\hline $\mathrm{A} 2$ & A. suis \\
\hline A23 & A. suis \\
\hline $\mathrm{A} 22$ & A. suis \\
\hline A 24 & A. suis \\
\hline A 25 & A. suis \\
\hline$A 3$ & A. suis \\
\hline A 53 & A. suis \\
\hline A71 & A. suis \\
\hline A2I & A. suis \\
\hline $\mathrm{A} 17$ & A. suis \\
\hline A 18 & A. suis \\
\hline A7 & A. suis \\
\hline A20 & A. suis \\
\hline A 52 & A. suis \\
\hline A5 & A. suis \\
\hline A8 & A. suis \\
\hline A 63 & A. lignieresii \\
\hline A 54 & A. suis \\
\hline A 16 & A. suis \\
\hline A19 & A. suis \\
\hline A 70 & A. suis \\
\hline A64 & A. lignieresii \\
\hline A4 & A. suis \\
\hline A6 & A. suis \\
\hline $\mathrm{A} 9^{*}$ & A. suis \\
\hline A $219^{*}$ & A. suis \\
\hline $\mathrm{A} 100^{*}$ & A. suis \\
\hline A153 & Actinobacillus sp. \\
\hline $\mathrm{A} 226^{*}$ & A. suis \\
\hline $\mathrm{A} 267^{*}$ & A. suis \\
\hline A274* & Actinobacillus sp. \\
\hline A 151 & Actinohacillus sp. \\
\hline A 152 & Actinobacillus sp. \\
\hline A 154 & Actinobacillus sp. \\
\hline A259* & A. suis \\
\hline $\mathrm{A} 260^{*}$ & Actinobacillus sp. \\
\hline A261* & Actinoba \\
\hline
\end{tabular}

Phenon 2: Actinohacillus equuli

$\begin{array}{ll}\text { A26* } & \text { A. equuli } \\ \text { A.36* } & \text { A. equuli } \\ \text { A.37* } & \text { A. equuli } \\ \text { A.34* } & \text { A. equuli } \\ \text { A31 } & \text { A. equuli } \\ \text { A32 } & \text { A. equuli } \\ \text { A33 } & \text { A. equuli } \\ \text { A35 } & \text { A. equuli } \\ \text { A255* } & \text { A. equuli } \\ \text { A256* } & \text { A. equuli } \\ \text { A257* } & \text { A. equuli } \\ \text { A258* } & \text { A. equuli } \\ \text { A264* } & \text { A. equuli }\end{array}$

Phenon 3: Satellite

Al42 Pasteurella sp.

Phenon 4: 'BLG'

A82 Pasteurella sp.

A83 Pasteurella sp.

A84* Pasteurella sp.

Phenon 5: 'Mair'

A10* Pasteurella sp.

A12* Pasteurella sp.

A14* Pasteurella sp.

Al ${ }^{*} \quad$ Pasteurella sp.
Source and

collection no. $\dagger$

Mair $1688 / 72$

Mair 13443/72

Mair

Mair

Mair

Mair

LPHL 15296/73

NCTC 10840

Ross 7038

Mair

Mair

Mair

Mair 1689/72

Mair

NCTC 10843

LPHL $18808 / 73$

LPHL $927 / 73$

ATCC 15557

NCTC 10841

Mair

Mair

Ross 1388

ATCC 15558

LPHL 25785

LPHL $18809 / 73$

LPHL 928/73

LPHL 20392/79

LPHL 32452/79

Cutlip 0164

LPHL 27894/79

LPHL $18808 / 73$

Cutlip 0186

Cutlip B15

Cutlip 0186

Cutlip 0203

LPHL 9339/78

LPHL $13028 / 78$

LPHL 13572/78

NCTC 8529

NCTC 8987

NCTC 9435

NCTC 8794

NCTC 8529

NCTC 3365

NCTC 8644

NCTC 8795

LPHL 40978/76

LPHL 9680/77

LPHL 19411/77

LPHL 209/78

NCTC 8795

LPHL 37706/74

NCTC 10547

NCTC 10548

NCTC 10549

LPHL $5143 / 70$

LPHL 14679/70

LPHL 34152/70

LPHL 7385/70
Comments†

Piglet. NCTC 10840; strain 3, Mair et al. (1974)

Piglet. NCTC 10843; strain 5, Mair et al. (1974)

Frederiksen P392

Frederiksen P391

Frederiksen P393

Frederiksen P247

Piglet lung abscess

Same strain as $\mathrm{Al}$

Source not recorded

Frederiksen P390

Frederiksen P379

Frederiksen P380

CEN. Piglet. NCTC 10841; strain 4, Mair et al. (1974)

Frederiksen P385

Same strain as A2

Piglet

Piglet septicaemia

Swine

Same strain as $\mathrm{A} 7$

Frederiksen P378

Frederiksen P381

Source not recorded

Swine

Source not recorded

Piglet

Piglet septicaemia

Swine

Source not recorded

Swine tonsil. D1895

Piglet

Replicate of A5

Swine tonsil. D1894

Swine spleen Cutlip et al. (1972), D1893

Replicate of A274

D1896

Horse

Horse

Mare

Foal. TAL, ATCC 19392, D1528. P157. J19

Foal septicaemia

Foal kidney

Foal septicaemia

Replicate of A26

Foal nephritis

Foal kidney abscess. P238

CEN. Foal septicaemia

Swine

CEN. Foal

Swine

Swine

Replicate of A35

D1884. Lung, tamarin monkey

Bovine lymphangitis, India

CEN. Bovine lymphangitis, India

Bovine lymphangitis. India

CEN. Pig foetus. NCTC 10699, D1187

Swine

Swine

Pig uterus. NCTC 10700 


\section{Table 1 (continued)}

$\begin{array}{ll}\begin{array}{l}\text { Strain } \\ \text { no. }\end{array} & \text { Name as received } \\ \text { A 179* } & \text { Pasteurella sp. } \\ \text { A13 } & \text { Pasteurella sp. } \\ \text { A278* } & \text { Pasteurella } \text { sp. } \\ \text { A15 } & \text { Pasteurella sp. } \\ \text { A204 } & \text { Pasteurella sp. } \\ \text { A212 } & \text { Pasteurella } \text { sp. }\end{array}$

Phenon 6: Actinobacillus lignieresil

$\begin{array}{lll}\text { A27* } & \text { A. lignieresii } & \text { NCTC } 4975 \\ \text { A202* } & \text { Actinobacillus sp. } & \text { D2146 } \\ \text { A263* } & \text { A. lignieresii } & \text { NCTC } 10563 \\ \text { A44* } & \text { A. lignieresii } & \text { NCTC } 10563 \\ \text { A40* } & \text { A. lignieresii } & \text { NCTC 4191 } \\ \text { A58 } & \text { A. equuli } & \text { ATCC } 13376 \\ \text { A283* } & \text { Actinobacillus sp. } & \text { Frederiksen P59 } \\ \text { A284* } & \text { Actinohacillus sp. } & \text { Frederiksen P59 } \\ \text { A285* } & \text { Actinobacillus sp. } & \text { Frederiksen P60 } \\ \text { A286* } & \text { Actinohacillus sp. } & \text { Frederiksen P60 } \\ \text { A28 } & \text { A. lignieresii } & \text { NCTC 4976 } \\ \text { A38* } & \text { A. lignieresii } & \text { NCTC 4976 } \\ \text { A59 } & \text { A. lignieresii } & \text { ATCC } 13369 \\ \text { A39 } & \text { A. lignieresii } & \text { NCTC 4189 } \\ \text { A46 } & \text { A. lignieresii } & \text { NCTC } 10565 \\ \text { A45 } & \text { A. lignieresii } & \text { NCTC } 10564 \\ \text { A41* } & \text { A. lignieresii } & \text { NCTC 4975 } \\ \text { A43* } & \text { A. lignieresii } & \text { NCTC } 10250 \\ \text { A42* } & \text { A. lignieresii } & \text { NCTC 4985 }\end{array}$

Phenon 7: Pasteurella haemolytaca biovar A

A90 $P$ hasmolitica A

Al02 $P$.haemolitica A

A91 $P$. hasmolitica A

Al01 $P$ haemolitica A

A94 $P$. haemolytica A

A95 $P$. haemolitica A

Al03 P. hoemolitica A

Al06 P. haemolitica A

A207* $P$.haemolytica A

Al04 P. hacmolitica T

A135 P. mastitidis

A96 P. hatemolitica

A137 Pasteurella sp

A223* P. haemolitica

A253* Pasteurella sp

A270* P. haternolitica A

A254* Pasteurella sp

A275* P. mastitidis

A97 P. hamolytica

Al05 P.haemolytica A

Al60 $P$ hamolitica

Al61 $P$. hatemolytica

Al26 Pasteurella sp.

Phenon 8: 'pneumotropica-gallinarum' group

A80* Pasteurella multocida

A86 P. pne'umomopica

Al40 Pasteuralla sp.

A 141 Pasteurella sp

A 132 P. gallinaram

A 133 P. gallinarum

A281* P. gallinarum

Phenon 9: Pasteurella haemolytica biovar $\mathrm{T}$

A92 P. haemolvtica T

A93 P. haemolitica $T$

A206* $P$.hasmolitica T

A208* P. haemolitica T
Source and

collection no.t

LPHL 9801/75

LPHL $18286 / 70$

LPHL $14679 / 70$

LPHL 34310/72

LPHL $49605 / 78$

LPHL 4376/79

TC 4975

NCTC 10563

ATCC 13376

Frederiksen P598

rederiksen $\mathrm{P} 601$

NCTC 4976

ATCC 13369

NCTC 10564

NCTC 10250

NCTC 10365

NCTC 10609

NCTC 10636

NCTC 9712

NCTC 10634

NCTC 10630

NCTC 10632

NCTC 10638

NCTC 10644

L.PHL 4585/79

NCTC 10640

ATCC 10899

NCTC 9380

D 1188

LPHL 25883/79

L.PHL $51807 / 78$

NCTC 10609

LPHL 51808/78

ATCC 10898

NCTC 10218

NCTC 10208

Frederiksen P174

Frederiksen $\mathrm{P} 4 \mathrm{Il}$

LPHL 28552

NCTC 8282

NCTC 8141

D1549

D 1549

ATCC 13361

ATCC 13361

NCTC 10370

NCTC 10369

LPHL 4584/79

LPHL 4586/79
ATCC 13360
Comments $\dagger$

Swine
Swine
Replicate of A 12
Piglet
Swine
Prairie marmot

Bovine lesion. D1529, J20, SM29

Ox lymph node, Leicester

Bovine tongue lesion. Serotype I

Replicate of A263

Bovine lesion

Horse joint. Wetmore straun 1706

$2008 / 76$

$339 / 77$

$1004 / 77$

204/78

Bovine lesions. ATCC 19393, D1530, J21, SM30

CEN. Replicate of A28

Wetmore KC208

Bovine lesion. TAL, P151

Sheep lung. Serovar 2

Bovine tongue. Serovar la

Bovine lesions

Bovine lymph node. Serovar la

Bovine lesions

Sheep. J171, SM20, serovar 2

Sheep. Serovar 1. ATCC 29696

Lamb pneumonia. Serovar 8. ATCC 29699

642/56, serovar 2, ATCC 29694

Lamb pneumonia. Serovar 7. ATCC 29698

Lamb pneumonia. Serovar 5. ATCC 29695

Sheep pneumonia. Serovar 6. ATCC 29697

CEN. Sheep nose. Serovar 9. ATCC 29700

Lamb nose. Serovar 12. ATCC 29702

Sheep lung

Sheep nose. Serovar 10. ATC 29706

Sheep

TAL. 1266/56, P586, serologically untypable

Rabbit snuffles, Leicester University animal house

Lamb lung

Sheep meningitis

Replicate of A90

Lamb pneumonia

Sheep

T185, serologically untypable

Lamb. Serovar 11. ATCC 29701

DI902, biovar 3

D1903, biovar 3

Source not recorded

Dog-bite in man. Parker 36735

Mouse lung. TAL, J169, SM18, P421

Source not recorded

Replicate of A 140

Chicken respiratory tract. NCTC 11187

CEN. TAL. Chicken sinus. NCTC 11188

Replicate of A 133

Lamb septicaemia. Serovar 3. ATCC 29703

Lamb septicaemia. Serovar 4. ATCC 29704

Sheep lung

Sheep lung 


$\begin{array}{cl}\begin{array}{c}\text { Strain } \\ \text { no. }\end{array} & \text { Name as received } \\ \text { A245* } & P \text {. haemolytica } \mathrm{T} \\ \mathrm{A}^{*} 44^{*} & \text { P. haemolytica } \mathrm{T} \\ \mathrm{A} 242^{*} & \text { P. haemolytica } \mathrm{T} \\ \mathrm{A} 243^{*} & \text { P. haemolytica } \mathrm{T}\end{array}$

Phenon 10: Pasteurella multocida

$\begin{array}{ll}\text { A72 } & \text { P. multocida } \\ \text { A79 } & \text { P. multocida } \\ \text { A73 } & \text { P. multocida } \\ \text { A74 } & \text { P. multocida } \\ \text { A76 } & \text { P. multocida } \\ \text { A78 } & \text { P. multocida } \\ \text { A75 } & \text { P. multocida } \\ \text { A85 } & \text { P. multocida } \\ \text { A77 } & \text { P. multocida } \\ \text { A113 } & \text { P. multocida } \\ \text { A112 } & \text { P. multocida } \\ \text { A118 } & \text { P. multocida } \\ \text { A114 } & \text { P. multocida } \\ \text { A117 } & \text { P. multocida } \\ \text { A136 } & \text { P. multocida } \\ \text { A143 } & \text { Pasteurella } \text { sp. } \\ \text { A213* } & \text { P. multocida } \\ \text { A107 } & \text { P. multocida } \\ \text { A111 } & \text { P. multocida } \\ \text { A218* } & \text { P. multocida } \\ \text { A225* } & \text { Pasteurella } \text { sp. } \\ \text { A269* } & \text { P. multocida } \\ \text { A222* } & \text { P. multocida } \\ \text { A108 } & \text { P. multocida } \\ \text { A185 } & \text { P. multocida } \\ \text { A186 } & \text { P. multocida } \\ \text { A187 } & \text { P. multocida } \\ \text { A109 } & \text { P. multocida } \\ \text { A110 } & \text { P. multocida } \\ \text { A182 } & \text { P. multocida } \\ \text { A205* } & \text { Pasteurella } \text { sp. } \\ \text { A214* } & \text { P. multocida } \\ \text { A115 } & \text { P. multocida } \\ \text { A116 } & \text { P. multocida } \\ \text { A183 } & \text { P. multocida } \\ \text { P1 }\end{array}$

\section{Table 1 (continued)}

Source and collection no.t

LPHL 51810/78

LPHL $51809 / 78$

LPHL 34876/76

LPHL 34880/76

NCTC 1877

NCTC 1737

NCTC 5868

NCTC 7460

NCTC 8565

NCTC 10722

NCTC 8281

NCTC 3195

NCTC 10382

NCTC 10325

NCTC 10324

NCTC 1876

NCTC 10326

NCTC 948

NCTC 2771

LPHL $37717 / 74$

LPHL 9606/79

NCTC 10203

NCTC 10323

LPHL 20717/79

LPHL 27397/79

NCTC 8565

LPHL 25786/79

NCTC 10201

LPHL 25034/75

LPHL 25677/75

LPHL 27202/75

NCTC 10202

NCTC 10322

D1944

LPHL $11183 / 79$

NCTC 1287

NCTC 2417

Wallace $75 / 56814$

Phenon 11 : Actinobacillus actinomycetemcomitans
A290* A. actinomycetemcomitans
NCTC 9709
A29T* A. actinomycetemcomitans
A30* A. actinomycetemcomitans
NCTC 9709
NCTC 9710

Phenon 12: Satellite

$\begin{array}{ll}\text { A163 } & \text { 'Pasteurel } \\ \text { Phenon 13: 'Pasteurella } \\ \text { A99 } & \text { 'P. bettii' } \\ \text { A119* } & \text { 'P. bettii' } \\ \text { A120* } & \text { 'P. bettii' } \\ \text { A271* } & \text { 'P. bettii' }\end{array}$

Phenon 14: 'Actinobacillus seminis'

$\begin{array}{ll}\text { A51* } & \text { 'A. seminis' } \\ \text { A65* } & \text { 'A. seminis' } \\ \text { A280* } & \text { 'A. seminis' } \\ \text { A166* } & \text { 'A. seminis' } \\ \text { A164* } & \text { 'A. seminis' }\end{array}$

A 164* 'A seminis'

Phenon 15: "Pasteurella haemolytica va

A87 'P. haemolytica var. ureae

A236* 'P. haemolytica var, ureae'

A235* 'P. haemolytica var. ureae'

A246 P. ureae

A234* 'P. haemolytica var. ureae'

A273* 'P. haemolytica var. ureae'

A98*

\section{Eleazer LM}

NCTC 10535

NCTC 10534

NCTC 10536

NCTC 10535

NCTC 10851

ATCC 15768

NCTC 10851

Van Tonder 70-64

Van Tonder 6201

NCTC 10222

NCTC 10221

NCTC 10220

LPHL $3901 / 78$

NCTC 10219

NCTC 10222

NCTC 10219
Comments ${ }^{\dagger}$

CEN. Lamb septicaemia

Lamb septicaemia

Calf lung

Calf lung

Sheep

Pig. Cornelius serological group III

Cattle

Cow

Turkey liver

Bovine

Dog-bite in man. Parker 36734

Bovine. ATCC 19427, J167, SM15

Human finger

Bovine. Carter serological group D

Deer. Carter serological group $\mathrm{C}$

Rabbit. Cornelius serological group IV

Bovine. Carter serological group $\mathbf{E}$

Mouse. Cornelius serological group II

Cat-bite in man. 21429

Brown hopping mouse

Cat-scratch in man. Frederiksen var. 5

CEN. Bovine. Roberts serovar I

Bovine. Carter serological group B

Human meningitis

Hedgehog

Replicate of A76

Cat-bite in man

Avian isolate. Roberts serovar II

Source not recorded

Source not recorded

Source not recorded

Deer. Roberts serovar III

Pig. TAL, P427. Carter serological group A

Ferret, Leicester University animal house

Ferret nose, Leicester University animal house

Human nasal sinus

Calf pneumonia. Jones serological group III

Rabbit. Cornelius serological group I

Human abscess from lion mauling. D1943

Human abscess. Opaque colonial variant of A29T

CEN. Translucent colonial variant of A29O

Human abscess. TAL

Mallard duck. D1911

Bartholin cyst. ATCC 23273, CDC 41-5568

Urine. ATCC 23275, CDC 41-9471

CEN. Infected finger. ATCC 23274, CDC 41-7170

Replicate of $\mathrm{A} 99$

CEN. Ovine semen, ATCC 15768

Same strain as NCTC 10851

Replicate of A51

D1914

D1912

Nose of patient with bronchitis. ATCC 29693, J170

CEN. Rhinosinusitis ATCC 29692

Rhinosinusitis. ATCC 29691

Source not recorded

Ozaena. TAL, ATCC 25976, P161

Replicate of A87

Replicate of A234 
Table 1 (continued)

Strain

no. Name as received

Phenon 16: Satellite

A241* Pasteurella sp.

Phenon 17: 'Ross'

A55 Actinobacillus sp.

A68 Actinobacillus sp.

A56* Actinobacillus sp

A66* Actinobacillus sp

A69* Actinobacillus sp.

A67 Actinobacillus sp.

A176 Actinobacillus sp.

A180* Actinobacillus sp.

A247* Aerogenic pasteurella

A248* Aerogenic pasteurella

A276* Actinobacillus sp.

Phenon 18: Satellite

A150* Pasteurella sp.

Phenon 19: Satellite

A217* Pasteurella pneumotropica

Phenon 20: Pasteurella aerogenes

A81* Pasteurella pneumotropica

A240* P.pneumotropica

A272* $\quad P$. pneumotropica

A146 P. pneumotropica

A211 Actinobacillus sp.

A221* P. aerogenes

A268* $P$. aerogenes

A224* Pasteurella sp.

A203* Pasteurella $\mathrm{sp}$.

A238* $\quad P$. pneumotropica

A239* P. pneumotropica

A215* Pasteurella sp.

A251* Aerogenic pasteurella

Phenon 21: Satellite

Al44 Pasteurella pneumotropica

Phenon 22: 'aerogenic group 2'

A148 Pasteurella $\mathrm{sp}$.

A209* Pasteurella sp.

A210* Pasteurella $\mathrm{sp}$.

A249* Aerogenic pasteurella

A250* Aerogenic pasteurella

Phenon 23: Satellite

A252* Pasteurella sp.

Phenon 24: Tortoise

A220* Pasteurella sp.

A266* Pasteurella sp.

Phenon 25: 'ent-b'

A $121 \quad$ Yersinia enterocolitica

A122 Y.enterocolitica

A181 Y.enterocolitica

A189Y. enterocolitica

Phenon 26: Yersinia enterocolitica

A123 Y. enterocolitica

A124 Y.enterocolitica

A191 Y. enterocolitica

A195 Y.enterocolitica

A194 Y.enterocolitica

A196 Y.enterocolitica

A197 Y. enterocolitica

A199 Y. enterocolitica

A200 $\quad Y$. enterocolitica

A171T Y.enterocolitica

A1710 Y.enterocolitica
Source and

collection no. +

LPHL 4345I/77

NCTC 10801

Ross 192

NCTC 10802

Ross 63

Ross 200

Ross 145

LPHL 32587/74

LPHL 48057/75

LPHL 43104/76

LPHL $46377 / 76$

Ross J45

LPHL 46139

LPHL 17749/79

NCTC 10603

LPHL 48127/78

Hooper 3

Hooper 3

LPHL 7745/79

ATCC 27883

ATCC 27883

LPHL 27396/79

D2147

LPHL 8832/76

LPHL $50833 / 77$

LPHL 12744/79

LPHL 49750/77

Hooper 1

Hooper 5

LPHL 6052/79

LPHL 6053/79

LPHL 40026/77

LPHL $41889 / 77$

LPHL 51811/78

LPHL 18329/79

LPHL 18329/79

Mollaret 38

Mollaret 225

NCTC 10460

Mollaret YeI98

Mollaret 356

Mollaret 340

Mollaret Ye206

Mollaret Ye217

Mollaret Ye216

Mollaret Ye241

Mollaret Ye244

Mollaret Ye250

Mollaret Ye252

NCTC 10461

NCTC 10461
Comments $†$

Dog-bite in man

Sow vagina. Ross 192, ATCC 27072, Frederiksen P624

Sow vagina, Same strains as A55

CEN. Sow vagina. Ross 63, ATCC 27073,

Frederiksen P636

Sow vagina. Same strain as A56

Sow vagina. ATCC 27075

Sow vagina. ATCC 27074, Frederiksen P647

Aborted pig foetus stomach

Sow vagina

Aborted pig foetus stomach

Aborted pig foetus

Replicate of $\mathrm{A67}$

Swine

Swine

Rabbit lung. Andre strain 9022

CEN. Hamster

Rat mouth. D1888

Replicate of A272

Pig liver

TAL. Swine intestine

Replicate of A221

Rabbit

Rat pneumonia, Leicester University animal house

From mouse

'Shaws Jird'

Eland calf

Mara

Laboratory rodent. D1886

Guinea pig colitis. D1890

CEN. Man, bite of mara

Man, bite of mara

Guinea pig

Wallaby

Dog eye

Tortoise

Replicate of A220

Hare. D1703

CEN. Hare. D1708

Chinchilla. Ye91, D1947, 871

Chinchilla. Biovar 5

Monkey. D1737

Man. D1747

Man. Biovar 5

Man

CEN. Man

Man. Biovar 4

Man. Biovar 4

Man. Biovar 4

Man

Chinchilla. Ye96, P76

Opaque colonial variant of A171T 


\section{Table 1 (continued)}

Strain
no

Name as received

A198

A 175

A 172

A 173

A265*

A 125

A 193

A201

A174

A 190

\section{$Y$. enterocolitica}

$Y$. enterocolitica

$Y$. enterocolitica

$Y$. enterocolitica

$Y$. enterocolitica

$Y$. enterocolitica

$Y$. enterocolitica

$Y$. enterocolitica

$Y$. enterocolitica

$Y$. enterocolitica

Phenon 27: Yersinia pseudotuherculosis

A127 Y.pseudotuberculosis

A128 Y.pseudotuberculosis

A129 Y.pseudotuberculosis

Al30 Y.pseudotuberculosis

A229* Y.pseudotuberculosis

A231* Y.pseudotuberculosis

A232* Y.pseudotuberculosis

A233* $\quad Y$. pseudotuberculosis

A230* Y. pseudotuberculosis

A262* Y.pseudotuberculosis

A279* Yersinia sp.

Phenon 28: Satellite

A 159 Yersinia sp.

Phenon 29: Yersinia pestis

$\begin{array}{lll}\text { A138 } & \text { Y.pestis } & \text { D1754 } \\ \text { Al39 } & \text { Y.pestis } & \text { D1754 }\end{array}$

Phenon 30: 'past-b'

A89 Pasteurella haemolytica $\mathrm{T}$

A165 'Actinobacillus seminis'

A184 Pasteurella sp.

Phenon 31: Yersinia philomiragia

A155 Y.philomiragia

A156 Y.philomiragia

A157 Y.philomiragia

A277* Y.philomiragia

Phenon 32: Moraxella anatipestifer

A131* 'Pasteurella anatipestifer'

A282* 'P. anatipestifer

A 162* 'P. anatipestifer
Source and

collection no. $\dagger$

Mollaret Ye247

Mollaret Ye195

NCTC 10462

NCTC 10463

Mollaret Ye244

LPHL 22790/70

Mollaret Ye211

Mollaret Ye253

NCTC 10598

Mollaret Ye203

Mair 4100

Mollaret 773

Smith 1074

Mair 298

Mair 4100

Smith 1074

Mair 298

Mollaret 75

Mollaret 773

Mollaret 773

Holmes 573/74

Holmes 573/74

D 1754

D1754

NCTC 10371

Van Tonder T981 V

Jackson CM48770

ATCC 25015

ATCC 25016

ATCC 25017

ATCC 25017

ATCC 11845

ATCC 11845

Eleazer 1533
Comments†

Man. Biovar 4

Chinchilla

Chinchilla. D1671, Ye92, P72

Chinchilla. D1674, Ye97, P77

Replicate of A197

D1752

Man. Biovar 5

Man

Man. ATCC 23715, Ye636, Billups 1803-68

Hare. Biovar 5

Rabbit. D1535, M39. Serovar IIA

Hare. Serovar IIB, D1536, M43

Mink. DI537, M49. Serovar III

Guinea pig. D1538, M51. Serovar IV

Replicate of A127

CEN. Replicate of A129

Replicate of A130

Guinea pig. Serovar V. D1540, M57

Replicate of A128

Replicate of A128

D1901

Replicate of A279

CEN. Nonvirulent strain, M18

CEN. Replicate of A138

CEN. Lamb septicaemia. J172

D1913

D1931

TAL. D1897. Moribund muskrat

D1898. River water

CEN. D1899. River water

Replicate of A157

TAL. CEN. Duck septicaemia. NCTC 11014

Replicate of A131

Mallard duck. D1910

* Strains thus marked were tested in a second batch of media (see text).

$\dagger$ Sources and abbreviations: CEN, control type of phenon: TAL, type strain in Approved Lists of Bacterial Names (Skerman et al., 1980); Mair, Dr N. S. Mair, Leicester University, UK ; LPHL, Leicester Public Health Laboratory, UK ; Frederiksen, Dr W. Frederiksen, State Serum Institute, Copenhagen, Denmark; Ross, Dr R. F. Ross, Veterinary Medical Research Institute, Iowa State University, Ames, Iowa, USA; Smith, Professor J. E. Smith, University of Surrey, Guildford, UK ; NCTC, National Collection of Type Cultures, Colindale, London, UK: ATCC, American Type Culture Collection, Rockville, Md., USA; Holmes, Dr B. Holmes, National Collection of Type Cultures, Colindale, London, UK; D numbers, numbers in the Collection of the Microbiology Department University of Leicester; Cutlip, Dr R. C. Cutlip. USA Department of Agriculture Research Station, Ames, Iowa, USA: Hooper, Dr A. Hooper, Imperial Cancer Research Fund Laboratory, Lincoln's Inn Fields. London WC2A 3PX, UK; J numbers, from Johnson \& Sneath (1973); Mollaret, Dr H. H. Mollaret, Institut Pasteur, Paris, France; Van Tonder, Dr E. M. Van Tonder, Regional Veterinary Investigation Centre, Middelburg Cape, South Africa: Eleazar, Dr T. H. Eleazar, Clemson University, Columbia, SC 29202. USA: Wallace, Dr J. Wallace, Public Health Laboratory, Lincoln, UK.

determined by maintaining $10 \mathrm{ml}$ amounts of inoculated $\mathrm{BMB}$ at $56{ }^{\circ} \mathrm{C}$ for 15 and $30 \mathrm{~min}$; after $24 \mathrm{~h}$ incubation at $37{ }^{\circ} \mathrm{C}$ the cultures were plated onto blood agar and examined for growth after $24 \mathrm{~h}$.

Growth on special media and inhibitors. Tolerance of inhibitory compounds was tested in Replidishes. Visible growth on BMA containing 3, 4, 5,6,7 and $8 \%(\mathrm{w} / \mathrm{v}) \mathrm{NaCl}$ was recorded after $48 \mathrm{~h}$. Visible growth was recorded after $48 \mathrm{~h}$ on BMA containing $0.1 \%$ and $1 \%(\mathrm{v} / \mathrm{v})$ Teepol $\mathrm{L}(\mathrm{BDH}) ; 0.75 \%(\mathrm{w} / \mathrm{v})$ sodium arsenate; 9 p.p.m. $(\mathrm{w} / \mathrm{v})$ acriflavine; 10 p.p.m $(\mathrm{w} / \mathrm{v}) 4,4^{\prime}$-diamidinodiphenylamine: $0 \cdot 3 \%(\mathrm{w} / \mathrm{v})$ boric acid: $1 \%(\mathrm{v} / \mathrm{v})$ tributyrin: 200 and 30 
p.p.m malachite green; $0.01,0.02$ and $0.05 \%(\mathrm{w} / \mathrm{v})$ sodium azide; $0.07 \% \mathrm{CuSO} 4.5 \mathrm{H}_{2} \mathrm{O} ; 10$ p.p.m (w/v) brilliant green; 2 p.p.m (w/v) crystal violet; and $0.05 \%(\mathrm{w} / \mathrm{v})$ potassium tellurite. Reduction of tellurite was recorded as blackening. Growth in BMB containing $0.1 \%(\mathrm{w} / \mathrm{v})$ potassium tetrathionate, and reduction of tetrathionate (yellow colour) were recorded after $3 \mathrm{~d}$. Visible growth was recorded after $48 \mathrm{~h}$ on MacConkey agar (Oxoid), deoxycholate-citrate agar (Oxoid), and TCBS agar (Oxoid). Growth on violet red bile agar (Oxoid) and precipitation of bile salts were recorded after $48 \mathrm{~h}$.

Reduction of tetrazolium was tested by incorporating $0.1 \%$ and $0.01 \%(w / v) 2,3,5$-triphenyltetrazolium chloride and $1 \%(\mathrm{w} / \mathrm{v})$ glucose in BMA adjusted to $\mathrm{pH} 6 \cdot 0$. The inoculated plates were incubated for $48 \mathrm{~h}$ aerobically or anaerobically (GasPak, Becton-Dickinson). Red or white colonies were noted and reduction was scored if the surrounding medium also became red. Growth in BMB containing methylene blue 200 p.p.m or janus green 80 p.p.m was recorded $48 \mathrm{~h}$ after inoculation. Reduction of the dyes and gas production were also noted. Acidity or alkalinity on BMA containing bromothymol blue and buffered to $\mathrm{pH} 7.0$ (green) was recorded at $48 \mathrm{~h}$.

Biochemical tests. The methyl-red and Voges-Proskauer tests were done at 25 and $35^{\circ} \mathrm{C}$ after $7 \mathrm{~d}$ on cultures of BMB containing $0.5 \%(w / v) \mathrm{K}_{2} \mathrm{HPO}_{4}$ and $0.5 \%(\mathrm{w} / \mathrm{v})$ glucose. For the Voges-Proskauer test an equal amount of $40 \%(\mathrm{w} / \mathrm{v}) \mathrm{KOH}$ and a few drops of $1 \%(\mathrm{w} / \mathrm{v}) \alpha$-naphthol were added, and a red colour recorded as positive. The Voges-Proskauer test was also recorded after $48 \mathrm{~h}$ in the API50E galleries according to the manufacturer's instructions. Catalase was detected by emulsifying $24 \mathrm{~h}$ colonies from BMA in $3 \%(\mathrm{v} / \mathrm{v}) \mathrm{H}_{2} \mathrm{O}_{2}$ and recording bubbles. Oxidase was tested by the method of Kovacs (1956) on growth from $24 \mathrm{~h}$ cultures on BMA and a purple colour within $20 \mathrm{~s}$ was scored as positive. Indole production was tested after $48 \mathrm{~h}$ in BMB by the method of Cowan (1974). Production of $\mathrm{H}_{2} \mathrm{~S}$ from $\mathrm{BMB}$ after $2 \mathrm{~d}$ was detected by lead acetate paper, and $\mathrm{H}_{2} \mathrm{~S}$ in triple sugar iron agar (Oxoid) after $7 \mathrm{~d}$. Nitrate reduction was tested after $7 \mathrm{~d}$ by the method of Cowan (1974) on BMB containing $0 \cdot 1 \%$ $(\mathrm{w} / \mathrm{v}) \mathrm{KNO}_{3}$ and Durham tubes were included to test for gas production: destruction of nitrite was tested by the same method on BMB containing 0.01 and $0.001 \%(w / v) \mathrm{NaNO}_{2}$.

Gelatin liquefaction after $5 \mathrm{~d}$ was determined by inoculation of BMB containing $12 \%(\mathrm{w} / \mathrm{v})$ gelatin and cooling to $4{ }^{\circ} \mathrm{C}$ before reading. Tributyrin hydrolysis was recorded as clear zones on BMA containing $1 \%(\mathrm{v} / \mathrm{v})$ tributyrin after $48 \mathrm{~h}$. Hydrolysis of casein was detected by the method of Cowan (1974) by streaking on agar plates composed of one part of skim milk medium (Difco) with one part of double strength BMA, and examining for clearing after $48 \mathrm{~h}$. Hydrolysis of Tweens $20,40,60$ and 80 was tested as clearing at $48 \mathrm{~h}$ on plates containing $1 \%(\mathrm{v} / \mathrm{v}) \mathrm{Tween}$. Digestion of tyrosine $(0.5 \%, \mathrm{w} / \mathrm{v})$ in BMA was detected as a turbid zone after $48 \mathrm{~h}$.

Urease was determined on the medium of Cowan (1974) after $2 \mathrm{~d}$, and also recorded in the API50E galleries after $24 \mathrm{~h}$. Phosphatase was determined by the method of Cowan (1974) after $7 \mathrm{~d}$ incubation on BMA containing $0.01 \%(\mathrm{w} / \mathrm{v})$ phenolphthalein diphosphate sodium salt as a red colour on flooding with strong ammonia solution. Lecithinase was determined after $48 \mathrm{~h}$ as turbidity in plates of BMA containing egg yolk emulsion (Oxoid SR 47; $1 \%, \mathrm{v} / \mathrm{v}$, added after cooling to $55^{\circ} \mathrm{C}$ ), after flooding with $1 \%(\mathrm{w} / \mathrm{v}) \mathrm{CuSO}_{4} \cdot 5 \mathrm{H}_{2} \mathrm{O}$. Deoxyribonuclease was detected on DNAase agar (Oxoid CM321) by flooding with $1 \mathrm{M}-\mathrm{HCl}$ after $5 \mathrm{~d}$ incubation and examining for clearing; orange and brown fluorescence under UV light $(366 \mathrm{~nm})$ was also recorded. Aesculin hydrolysis was determined in the API galleries after $24 \mathrm{~h}$.

Lysine and ornithine decarboxylases, arginine dihydrolase and tryptophan deaminase were recorded in API50E galleries after $24 \mathrm{~h}$ according to the manufacturer's instructions. Citrate utilization was determined by the method of Christensen as modified by Cowan (1974) as growth at $48 \mathrm{~h}$, and also in the API50E galleries (see below) according to the manufacturer's instructions. $o$-Nitrophenyl $\beta$-D-galactopyranoside (ONPG) hydrolysis was recorded in the galleries after $24 \mathrm{~h}$. Production of levan as mucoid growth, and acidity on BMA containing $5 \%$ $(w / v)$ sucrose and 30 p.p.m bromothymol blue were determined after $2 \mathrm{~d}$ incubation. Gas from glucose was recorded at $48 \mathrm{~h}$ in BMB containing $1 \%(\mathrm{w} / \mathrm{v})$ glucose and a Durham tube and in the medium of Hugh \& Leifson (1953). Fermentative reaction and alkalinity were also determined in the latter medium after $48 \mathrm{~h}$ : decolorization of the indicator at $48 \mathrm{~h}$ was also recorded.

Production of acid from carbohydrates, etc. Acid production from carbohydrates was determined in API50E galleries (phenol red as indicator) according to the manufacturer's instructions: growth from overnight cultures on BMA was suspended in API50E medium to give the turbidity of McFarland standard 2; cupules were inoculated and acidity was recorded at $24 \mathrm{~h}$.

Numerical taxonomy. Computing was done on the University of Nottingham's ICL 1900 computer and the University of Leicester's CDC CYBER computer using programs written by M. J. Sackin and associates of the Microbiology Department, Leicester University.

The $t \times n$ matrix consisted of strains scored for 155 characters, after excluding eight invariant characters (see Table 3). Most characters were coded 0 for negative and 1 for positive. The characters from the API kits were coded from 0 for negative to 5 for a strong positive reaction. The similarity coefficients used were the Gower coefficient $\left(S_{G}\right)$, the Simple Matching coefficient $\left(S_{S M}\right)$ and the Pattern Difference $\left(D_{P}\right)$. Single Linkage and average linkage (UPGMA) cluster analyses were done and the vigour of each strain was calculated. Details of these methods are given in Sneath \& Sokal (1973). For $D_{P}$ and $S_{S M}$ the multistate characters were converted to binary ones; for the API50E results $0-2$ were scored negative and 3-5 positive. 
Test reproducibility was estimated by limited replication of the tests, and by duplication of some strains. These duplicate strains were carried through as independent strains, and their identities are shown in Table 1. Two strains (A29, A 171) showed pronounced colony variants, which were purified and carried through the study separately. Test error was calculated by formulae $I$ and 4 in Sneath \& Johnson (1972). It was found necessary to do this study in two separate stages, whereby about half the strains were tested on the first occasion, and the remainder on a second occasion with a different batch of culture media. The strains examined on the second occasion, therefore, are marked with asterisks in Table 1.

Other calculations. The overlap statistics of the phenons were calculated by the computer program OVCLUST (Sneath, 1979a). In this, the number of operational taxonomic units (OTUs) in each phenon, and the inter- and intra-group distances $d$ [based on the relation $d=\checkmark\left(1-S_{S M}\right)$ ] are used to calculate an index of overlap, $V_{G}$. This overlap can then be tested for significance against a chosen critical level of overlap, $V_{c r i t}$, by a non-central $t$-test. The test is not available if either phenon contains only one OTU.

The program DIACHAR (Sneath, 1980a) was used to list the most diagnostic characters of phenons, and the program CHARSEP was used to calculate VSP separation indices (Sneath, 1979b) so as to list the characters in order of their diagnostic value. The program MOSTTYP (Sneath, 1980b) was used to confirm that good identifications could be made from an indentification matrix of phenon percentage properties, and the program OVERMAT (Sneath, 1980c) was used to check overlap in this, by the same statistics as OVCLUST.

The principal coordinates analysis was made by the method of Gower (1966) from the taxonomic distances, $d$, between the centroids of the phenons (Table 2), using a program written by M. J. Sackin. In order to position the satellite strains (singletons), these were included as phenons of one OTU.

The amount of distortion between the similarities in the similarity matrix and the corresponding similarities implied by the phenogram was assessed by the cophenetic discrepancy $\Delta_{j}$ as calculated by Sneath et al. (1981).

\section{RESULTS}

\section{Test reproducibility}

There were four classes of duplicated strains: $(a)$ nine replicates on the same batch of medium; (b) 20 replicates where one was tested on the first batch of medium and the other on the second batch; $(c)$ two cases where two colony variants were tested on the same batch of medium; and $(d)$ six instances where the same isolate was received from different donors and tested on the same batch of medium. The mean percentage $S_{S M}$ values of the duplicated pairs, with standard deviations, were $(a) 90 \cdot 3 \pm 4 \cdot 0 ;(b) 87 \cdot 7 \pm 3 \cdot 2 ;(c) 96.0 \pm 0 \cdot 3 ;(d) 93 \cdot 1 \pm 1 \cdot 2$. The test error $p$ is best estimated from $(a)$ and $(b)$, and this gives a rather high value for $p$ of about $6.1 \%$.

The mean difference in vigour between replicates of all the four classes $(a)$ to $(d)$ was much the same, averaging about 0.03 . The two batches of medium did not differ significantly in the ease with which tests became positive, as judged by cases where one replicate was on one batch and the other on the other batch of medium (difference in means 0.008 ).

The batch of medium had no pronounced effect on the position of strains within the clusters. There was a noteworthy effect only in phenon 27 , where strains tested in the second batch (including some replicates) are in the lower half of the phenon (Table 1).

\section{Main cluster analysis}

The UPGMA analysis with $S_{G}$ (Fig. 1) is used as the basis for the taxonomic description. Twenty-four groups of strains were considered reasonably distinct, and in addition there were eight satellites, which were treated as single-membered phenons. Phenons 24 and 29, though based on replicates of single strains, have been retained formally as separate phenons, as they give an indication of the variability due to the lack of complete test reproducibility. These are numbered as phenons $1-32$ in Table 1 . There were three main areas: $\mathrm{A}$, the actinobacilli and pasteurellas (phenons 1-24); B, the yersinias (phenons 25-29); and C, a miscellaneous group (phenons 30-32).

\section{Description of phenons}

Constituent strains of phenons are shown in Table 1. The parameters of the phenons, with intercentroid distances, are shown in Table 2. The percentages of positive test reactions are given in Table 3. 

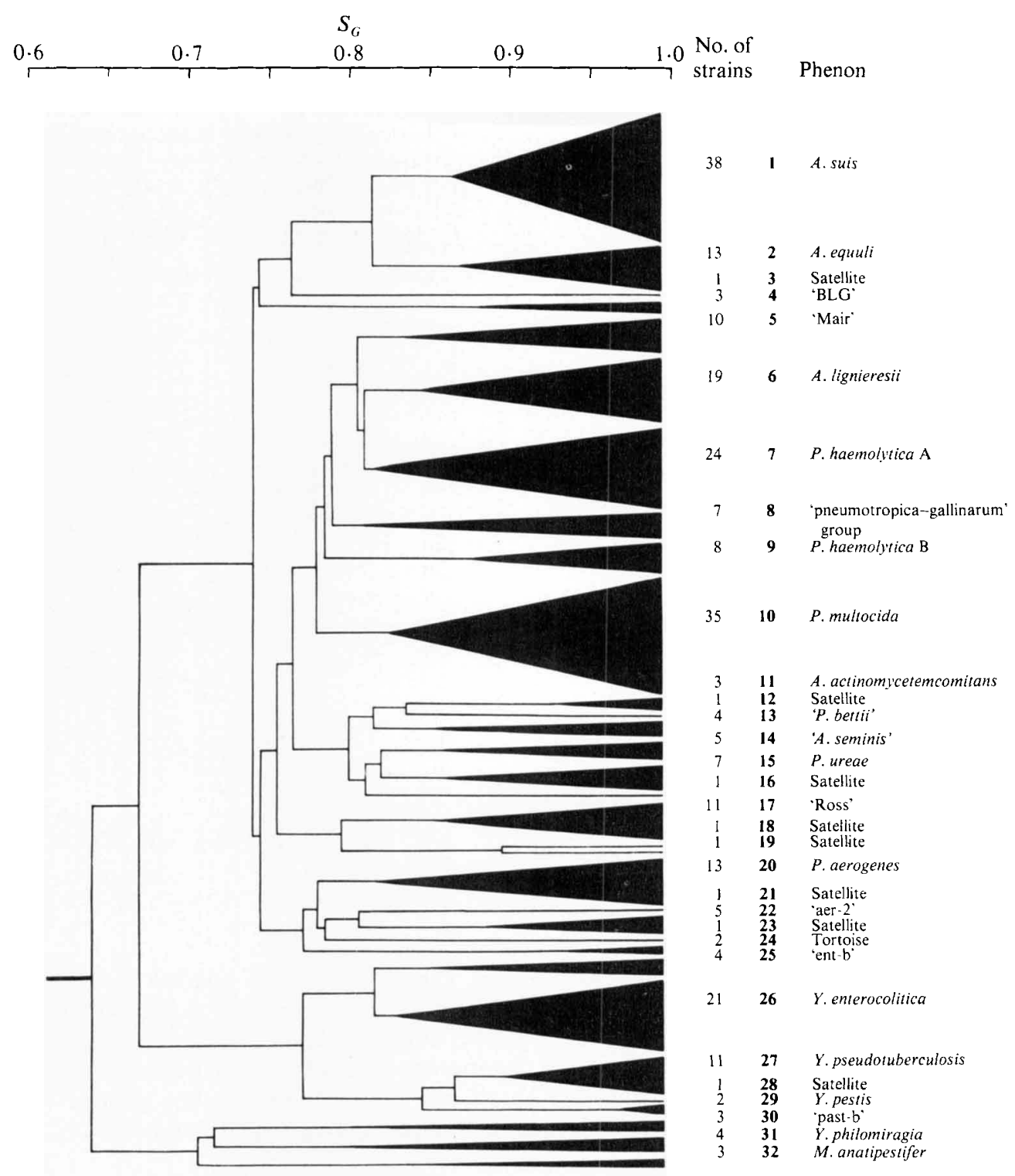

Phenon

.


Table 2. Parameters of phenons and intracentroid distances

The values are from data converted to positive and negative scores (see Methods). The entries in the body of the table are the intercentroid distances, $d=、\left(1-S_{S M}\right)$, from which Fig. 2 was derived. The mean vigour of each phenon is the mean proportion of characters with positive states, and SD is the standard deviation of the vigour of the strains. The mean distance of strains of a phenon to their own centroid is $d_{l}$, calculated as $、\left(\sum d_{c}^{2} /\left(t_{J}-1\right)\right)$, where $d_{c J}^{2}$ is the squared distance of a strain to the centroid of phenon $J$, and $t_{J}$ is the number of strains in $J$. It can be shown (Sneath, 1974) that $d_{J}$ is $、\left[\frac{1}{2}\left(1-\bar{S}_{S M}\right)\right]$, where $\bar{S}_{S M}$ is the mean intraphenon $S_{S M}$ obtained as the mean of the $t_{J}\left(t_{J}-1\right) / 2$ intraphenon $S_{S M}$ values. NA, Not applicable.

\begin{tabular}{|c|c|c|c|c|c|c|c|c|c|c|c|c|c|c|c|}
\hline \multicolumn{16}{|c|}{ Phenon } \\
\hline 2 & .277 & & & & & & & & & & & & & & \\
\hline 3 & .416 & .450 & & & & & & & & & & & & & \\
\hline 4 & .399 & .387 & .498 & & & & & & & & & & & & \\
\hline 5 & .381 & .325 & .503 & .380 & & & & & & & & & & & \\
\hline 6 & .335 & .247 & .484 & .391 & .248 & & & & & & & & & & \\
\hline 7 & .341 & .294 & .507 & .404 & .253 & .228 & & & & & & & & & \\
\hline 8 & .337 & .278 & .464 & .382 & .288 & .238 & .254 & & & & & & & & \\
\hline 9 & .407 & .360 & .521 & .390 & .335 & .320 & .277 & .317 & & & & & & & \\
\hline 10 & .402 & .320 & .476 & .389 & .293 & .281 & .287 & .270 & .307 & & & & & & \\
\hline 11 & .482 & .407 & .575 & .387 & .374 & .355 & .370 & .396 & .366 & .314 & & & & & \\
\hline 12 & .522 & .471 & .614 & .474 & .459 & .436 & .452 & .446 & .429 & .424 & .367 & & & & \\
\hline 13 & .492 & .408 & .537 & .412 & .373 & .340 & .387 & .373 & .377 & .338 & .326 & .421 & & & \\
\hline 14 & .476 & .408 & .560 & .439 & .383 & .379 & .377 & .398 & .378 & .356 & .373 & .371 & .317 & & \\
\hline 15 & .430 & .318 & .531 & .417 & .320 & .303 & .327 & .363 & .336 & .375 & .340 & .387 & .329 & .293 & \\
\hline 16 & .522 & .445 & .607 & .490 & .422 & .397 & .431 & .408 & .416 & .359 & .427 & .478 & .401 & .391 & .358 \\
\hline 17 & .384 & .365 & .541 & .399 & .309 & .315 & .306 & .363 & .403 & .372 & .426 & .489 & .392 & .382 & .396 \\
\hline 18 & .508 & .458 & .576 & .482 & .409 & .399 & .427 & .428 & .495 & .439 & .450 & .561 & .423 & .490 & .455 \\
\hline 19 & .500 & .433 & .586 & .474 & .357 & .360 & .386 & .418 & .426 & .380 & .433 & .503 & .358 & .441 & .390 \\
\hline 20 & .354 & .310 & .460 & .378 & .290 & .226 & .316 & .239 & .367 & .271 & .405 & .473 & .348 & .419 & .370 \\
\hline 21 & .452 & .431 & .523 & .502 & .439 & .373 & .448 & .384 & .489 & .466 & .512 & .570 & .439 & .528 & .505 \\
\hline 22 & .446 & .443 & .545 & .526 & .461 & .393 & $\begin{array}{r}.444 \\
\end{array}$ & .407 & .521 & .433 & .516 & .595 & .468 & .555 & .529 \\
\hline 23 & .454 & .416 & .547 & .488 & .436 & .417 & .430 & .399 & .482 & .427 & .475 & .570 & .442 & .490 & .472 \\
\hline 24 & .476 & .446 & .558 & .501 & .434 & .378 & .402 & .411 & .467 & .374 & .498 & .599 & .464 & .494 & .474 \\
\hline 25 & .465 & .447 & .464 & .405 & .387 & .374 & $\begin{array}{r}.424 \\
\end{array}$ & .395 & .445 & .394 & .482 & .559 & .436 & .486 & .471 \\
\hline 26 & .489 & .487 & .478 & .455 & .447 & .445 & .469 & .429 & .492 & .435 & .529 & .605 & .509 & .553 & .531 \\
\hline 27 & .476 & .492 & .497 & .389 & .500 & .471 & .504 & .464 & .516 & .472 & .538 & .594 & .510 & .540 & .534 \\
\hline 28 & .540 & .556 & .540 & .431 & .553 & .532 & .551 & $\begin{array}{l}.518 \\
.518\end{array}$ & .536 & .511 & .546 & .602 & .555 & .576 & .579 \\
\hline 29 & .532 & .562 & .546 & .467 & .543 & .520 & .496 & .478 & .516 & .477 & .543 & .627 & .540 & .582 & .582 \\
\hline 30 & .525 & .509 & .562 & .480 & .474 & .451 & .466 & .458 & .466 & .454 & .519 & .463 & .454 & .373 & .458 \\
\hline 31 & .523 & .476 & .593 & .540 & .498 & .457 & .470 & $\begin{array}{r}.430 \\
.469\end{array}$ & $\begin{array}{l}.460 \\
.462\end{array}$ & $\begin{array}{r}.424 \\
.426\end{array}$ & .485 & .448 & .472 & .435 & .453 \\
\hline 32 & .550 & .487 & .635 & .525 & .482 & .470 & .484 & .476 & .469 & .439 & .439 & .374 & .424 & .343 & .367 \\
\hline Phenon & 1 & 2 & 3 & 4 & 5 & 6 & 7 & 8 & 9 & 10 & 11 & 12 & 13 & 14 & 15 \\
\hline No. of strains & 38 & 13 & 1 & 3 & 10 & 19 & 24 & 7 & 8 & 35 & 3 & 1 & 4 & 5 & 7 \\
\hline Mean vigour & 0.451 & 0.384 & 0.438 & 0.332 & 0.350 & 0.340 & 0.342 & $0 \cdot 365$ & 0.292 & 0.323 & 0.235 & $0 \cdot 246$ & 0.230 & 0.182 & 0.235 \\
\hline $\mathrm{SD}$ & 0.021 & 0.015 & $\mathrm{NA}$ & 0.032 & 0.021 & 0.029 & 0.037 & 0.029 & 0.023 & 0.026 & 0.009 & $\mathrm{NA}$ & 0.022 & 0.035 & 0.023 \\
\hline$d_{i}$ & 0.225 & 0.240 & $\mathrm{NA}$ & 0.235 & 0.253 & 0.265 & 0.263 & 0.293 & 0.234 & 0.267 & 0.176 & $\mathrm{NA}$ & 0.244 & 0.236 & 0.234 \\
\hline
\end{tabular}

Phenon 5 is referred to as the 'Mair' group. These strains were isolated from swine in Leicestershire, UK, and given by Dr N. S. Mair. They were associated with abortions in sows, but may occur in other animals, because A.212, although rather peripheral, came from a marmot. They show a characteristic orange fluorescence on DNAase agar. Some other phenons showed a brown fluorescence (Table 3) but it was not very strong. The phenon is also characterized by being sensitive to malachite green and $1 \%$ Teepol, and is usually positive for ornithine decarboxylase.

Phenon 6 is Actinobacillus lignieresii, and diagnostic properties include reduction of nitrite, acid from mannitol, $\mathrm{D}(+)$-xylose and sucrose, but not from $\mathrm{L}(+)$-arabinose and trehalose.

Phenon 7 contains the strains of Pasteurella haemolytica biovar A, though strain A104 is recorded as biovar T (see Discussion). We found, as did Sakazaki et al. (1981), that they do not always acidify L-arabinose promptly. These strains are characterized by acidifying sorbitol and mannitol but not trehalose; they are sensitive to crystal violet.

Phenon 8 contains the type strains of both Pasteurella pneumotropica and Pasteurella gallinarum, and is referred to as the 'pneumotropica-gallinarum' group (for the distinction between these species, see Discussion). They are trehalose positive and mannitol negative, and grow on violet red bile agar and on $3 \% \mathrm{NaCl}$.

Phenon 9 consists exclusively of strains of $P$. haemolytica biovar T. They are characteristically catalase negative, sorbitol and trehalose positive but galactose negative and urease negative. They often showed delayed fermentation in Hugh \& Leifson medium.

Phenon 10. This large phenon corresponds to Pasteurella multocida. Characteristically, the strains are urease and ONPG negative, sensitive to $1 \%$ Teepol, but grow on $3 \% \mathrm{NaCl}$ and are usually sucrose and mannose positive. 
Table 2 (continued)

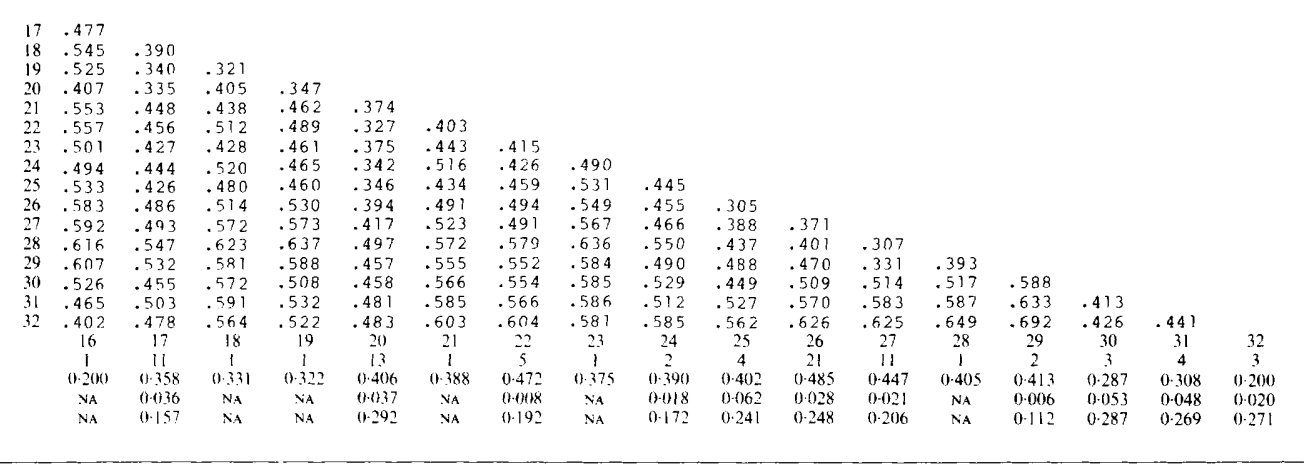

Phenon 11 is Actinobacillus actinomycetemcomitans. Strains are often coccoid. Sorbitol and mannitol are usually acidified, but not sucrose, $\mathrm{L}(+)$-arabinose or $\mathrm{D}(+)$-xylose. They are sensitive to azide and $3 \% \mathrm{NaCl}$. Phenon 12 is a satellite received as 'Pasteurella anatipestifer' but it is different phenotypically from phenon 32 . It is very sensitive to Teepol, but grows on tellurite and TCBS, and shows lipolytic activity on Tweens.

Phenon 13 comprises strains of 'Pasteurella bettii'. They have rather weak fermentative ability, being characteristically negative for galactose, sucrose, mannitol, $\mathrm{L}(+)$-arabinose and $\mathrm{D}(+)$-xylose, and are also urease and oxidase negative.

Phenon 14 comprises strains of 'Actinobacillus seminis', a bacterium implicated in epididymitis of rams (Baynes \& Simmons, 1960). It shows many negative test reactions, notably for mannose, maltose and phosphatase.

Phenon 15 is Pasteurella ureae. Strains are characteristically negative for galactose, $\mathrm{L}(+)$ arabinose and $\mathrm{D}(+)$-xylose, but mannitol positive. They are sensitive to janus green, malachite green and crystal violet.

Phenon 16 is an unidentified strain of Pasteurella which grew poorly and was nonfermentative in Hugh \& Leifson medium after short incubation, but it gave greening on blood agar, and $\mathrm{H}_{2} \mathrm{~S}$ from broth.

Phenon 17 is referred to as the 'Ross' group. It contains strains from the vagina of postparturient sows (Ross et al., 1972), and some similar strains isolated in England from aborted piglets in 1974-1976. The phenon is, however, quite distinct from $A$. suis or the 'Mair' group. It is characteristically inositol and sorbitol positive but sucrose negative. Janus green is reduced. 
Table 3. Characteristics of the phenons (percentage of strains positive)

NT, Not tested.

No. Character

Phenon ...

2

Colonial and morphological features

Constant characters: Gram-negative, greyish

semitransparent colonies (some variants were

more opaque, see Table 1)

1. Rods numerous

2. Coccobacilli numerous

3. Cocci numerous

4. Length $<1 \mu \mathrm{m}$

5. Length $1-2 \mu \mathrm{m}$

6. Length $>2 \mu \mathrm{m}$

7. Width $<0.25 \mu \mathrm{m}$

8. Width $0.25-0.5 \mu \mathrm{m}$

9. Width $0.5-1.0 \mu \mathrm{m}$

10. Straight-sided rods

11. Organisms predominantly single

12. Filaments present

13. Stain strongly with Gram counterstain

14. Bipolar stain marked

15. Extracellular slime in Gram stain

16. Motile $35^{\circ} \mathrm{C}$, hanging drop

17. Motile $35^{\circ} \mathrm{C}$, semisolid agar

18. Motile $25^{\circ} \mathrm{C}$, semisolid agar

19. Greening of sheep blood, $24 \mathrm{~h}$

20. Greening of sheep blood, $48 \mathrm{~h}$

21. Haemolysis of sheep blood, $24 \mathrm{~h}$

22. Haemolysis of sheep blood, $48 \mathrm{~h}$

$\begin{array}{llllllllll}100 & 100 & 100 & 100 & 100 & 63 & 100 & 100 & 88 & 63\end{array}$

$\begin{array}{llllllllll}51 & 85 & 100 & 33 & 60 & 84 & 73 & 43 & 88 & 82\end{array}$

$\begin{array}{llllllllll}13 & 8 & 0 & 0 & 0 & 32 & 13 & 13 & 13 & 36\end{array}$

$\begin{array}{llllllllll}94 & 100 & 100 & 100 & 100 & 73 & 100 & 71 & 100 & 91\end{array}$

$\begin{array}{llllllllll}100 & 92 & 100 & 100 & 89 & 42 & 77 & 86 & 50 & 40\end{array}$

$\begin{array}{rrrrrrrrrr}17 & 8 & 0 & 33 & 10 & 16 & 0 & 28 & 0 & 9\end{array}$

$\begin{array}{rrrrrrrrrr}3 & 8 & 0 & 0 & 10 & 0 & 5 & 28 & 0 & 9\end{array}$

$\begin{array}{rrrrrrrrrr}82 & 100 & 100 & 33 & 100 & 100 & 96 & 100 & 100 & 97\end{array}$

$\begin{array}{llllllllll}49 & 69 & 100 & 67 & 30 & 16 & 50 & 0 & 38 & 13\end{array}$

$\begin{array}{rrrrrrrrrr}97 & 100 & 100 & 100 & 89 & 91 & 95 & 100 & 100 & 100\end{array}$

$\begin{array}{llllllllll}82 & 92 & 100 & 100 & 70 & 63 & 55 & 71 & 63 & 60\end{array}$

$\begin{array}{llllllllll}97 & 92 & 0 & 100 & 60 & 32 & 36 & 28 & 38 & 20\end{array}$

$\begin{array}{llllllllll}66 & 31 & 0 & 100 & 80 & 63 & 86 & 86 & 88 & 54\end{array}$

$\begin{array}{llllllllll}77 & 77 & 100 & 33 & 20 & 21 & 36 & 13 & 25 & 26\end{array}$

$\begin{array}{rrrrrrrrrr}20 & 69 & 0 & 0 & 0 & 11 & 59 & 57 & 38 & 3\end{array}$

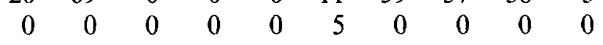

$\begin{array}{llllllllll}\text { NT } & \text { NT } & \text { NT } & \text { NT } & \text { NT } & \text { NT } & \text { NT } & \text { NT } & \text { NT } & \text { NT }\end{array}$

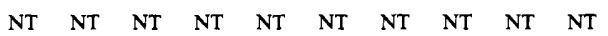

$\begin{array}{llllllllll}0 & 23 & 0 & 0 & 10 & 16 & 4 & 0 & 13 & 6\end{array}$

$\begin{array}{llllllllll}0 & 31 & 0 & 33 & 10 & 32 & 9 & 28 & 13 & 11\end{array}$

$\begin{array}{rrrrrrrrrr}100 & 0 & 0 & 0 & 40 & 21 & 70 & 0 & 38 & 0\end{array}$

$\begin{array}{llllllllll}100 & 0 & 0 & 0 & 70 & 21 & 70 & 0 & 50 & 3\end{array}$

Growth temperature and heat resistance

Constant characters: all grew at $37^{\circ} \mathrm{C}$; none

required added $\mathrm{CO}_{2}$ for reasonable growth.

23. Growth at $4{ }^{\circ} \mathrm{C}$

24. Growth at $10^{\circ} \mathrm{C}$

25. Growth at $15^{\circ} \mathrm{C}$

26. Growth at $45^{\circ} \mathrm{C}$

27. Resistance to $56^{\circ} \mathrm{C}, 15 \mathrm{~min}$

28. Resistance to $56{ }^{\circ} \mathrm{C}, 30 \mathrm{~min}$

Growth on special media and inhibitors

Constant characters: no white colonies on $0.1 \%$ tetrazolium anaerobically; all grew but gave no gas in methylene blue medium

29. Growth on $3 \% \mathrm{NaCl}$

30. Growth on $4 \% \mathrm{NaCl}$

31. Growth on $5 \% \mathrm{NaCl}$

32. Growth on $6 \% \mathrm{NaCl}$

33. Growth on $7 \% \mathrm{NaCl}$

34. Growth on $8 \% \mathrm{NaCl}$

35. Growth on Teepol L, $0.1 \%$

36. Growth on Teepol L, $1.0 \%$

37. Growth on arsenate

38. Growth on acriflavine

39. Growth on $4,4^{\prime}$-diamidinodiphenylamine

40. Growth on boric acid

41. Growth on tributyrin

42. Growth on malachite green, $30 \mathrm{ppm}$

43. Growth on malachite green, $200 \mathrm{ppm}$

44. Growth on sodium azide, $0.01 \%$

45. Growth on sodium azide, $0.02 \%$

46. Growth on sodium azide, $0.05 \%$

47. Growth on copper sulphate

48. Growth on brilliant green

49. Growth on crystal violet, $2 \mathrm{ppm}$

50. Growth on tellurite

51. Reduction of tellurite

$\begin{array}{rrrrrrrrrr}89 & 69 & 100 & 0 & 10 & 36 & 44 & 100 & 0 & 97 \\ 8 & 0 & 100 & 0 & 0 & 5 & 0 & 0 & 0 & 57 \\ 3 & 0 & 0 & 0 & 0 & 0 & 0 & 0 & 0 & 3 \\ 0 & 0 & 0 & 0 & 0 & 0 & 0 & 0 & 0 & 3 \\ 0 & 0 & 0 & 0 & 0 & 0 & 0 & 0 & 0 & 3 \\ 0 & 0 & 0 & 0 & 0 & 0 & 0 & 0 & 0 & 0 \\ 100 & 100 & 100 & 100 & 100 & 95 & 96 & 100 & 100 & 91 \\ 63 & 0 & 0 & 0 & 0 & 53 & 13 & 13 & 63 & 3 \\ 21 & 8 & 0 & 0 & 0 & 18 & 9 & 13 & 0 & 21 \\ 0 & 0 & 0 & 100 & 0 & 0 & 13 & 13 & 0 & 3 \\ 80 & 69 & 100 & 100 & 10 & 16 & 4 & 33 & 0 & 94 \\ 24 & 46 & 0 & 33 & 20 & 32 & 21 & 57 & 38 & 86 \\ 100 & 100 & 100 & 100 & 100 & 100 & 100 & 100 & 100 & 100 \\ 100 & 69 & 0 & 100 & 0 & 89 & 75 & 71 & 100 & 40 \\ 3 & 0 & 0 & 0 & 0 & 16 & 4 & 13 & 0 & 3 \\ 100 & 100 & 100 & 0 & 100 & 100 & 100 & 86 & 100 & 94 \\ 100 & 85 & 0 & 33 & 80 & 79 & 67 & 43 & 13 & 43 \\ 26 & 8 & 0 & 0 & 0 & 11 & 4 & 13 & 0 & 9 \\ 24 & 15 & 100 & 33 & 0 & 11 & 0 & 13 & 0 & 0 \\ 40 & 8 & 100 & 33 & 0 & 32 & 4 & 57 & 13 & 11 \\ 66 & 0 & 100 & 100 & 10 & 53 & 4 & 71 & 50 & 80 \\ 0 & 0 & 0 & 33 & 10 & 0 & 0 & 28 & 0 & 3 \\ 73 & 23 & 100 & 67 & 50 & 16 & 67 & 71 & 25 & 51\end{array}$


Table 3 (continued)

$\begin{array}{llllllllllllllllllllll}11 & 12 & 13 & 14 & 15 & 16 & 17 & 18 & 19 & 20 & 21 & 22 & 23 & 24 & 25 & 26 & 27 & 28 & 29 & 30 & 31 & 32\end{array}$

$\begin{array}{llllllllllllllllllllll}100 & 100 & 100 & 80 & 100 & 0 & 100 & 100 & 100 & 100 & 100 & 40 & 100 & 0 & 75 & 100 & 82 & 100 & \text { NT } & 100 & \text { NT } & 100\end{array}$ $\begin{array}{llllllllllllllllllllll}100 & 100 & 100 & 60 & 86 & 100 & 0 & 0 & 0 & 77 & 100 & 100 & 0 & 100 & 100 & 95 & 91 & 100 & \text { NT } & 0 & \text { NT } & 67\end{array}$ $\begin{array}{llllllllllllllllllllll}100 & 0 & 0 & 0 & 0 & 0 & 0 & 0 & 0 & 0 & 0 & 40 & 0 & \mathrm{NT} & 0 & 5 & 18 & 0 & \mathrm{NT} & 0 & 0 & 0\end{array}$ $\begin{array}{llllllllllllllllllllll}100 & 100 & 100 & 80 & 100 & 100 & 82 & 100 & 100 & 100 & 100 & 100 & 100 & 0 & 100 & 100 & 100 & 100 & \text { NT } & 50 & \text { NT } & 100\end{array}$ $\begin{array}{llllllllllllllllllllll}0 & 0 & 0 & 80 & 86 & 0 & 100 & 100 & 100 & 39 & 0 & 0 & 100 & 0 & 25 & 48 & 55 & 0 & \text { NT } & 100 & 0 & 33\end{array}$ $\begin{array}{llllllllllllllllllllll}0 & 0 & 0 & 80 & 43 & 0 & 73 & 0 & 0 & 8 & 0 & 0 & 100 & 0 & 0 & 5 & 27 & 0 & \text { NT } & 100 & 0 & 33\end{array}$ $\begin{array}{rlllllllllllllllllllll}67 & 100 & 50 & 0 & 13 & 0 & 9 & 100 & 100 & 23 & 0 & 20 & 0 & 0 & 0 & 0 & 0 & 0 & \text { NT } & 0 & 0 & 67\end{array}$ $\begin{array}{llllllllllllllllllllll}33 & 100 & 50 & 100 & 57 & 100 & 91 & 0 & 0 & 85 & 100 & 80 & 100 & 100 & 75 & 95 & 91 & 100 & \text { NT } & 100 & \text { NT } & 67\end{array}$ $\begin{array}{llllllllllllllllllllll}0 & 0 & 0 & 40 & 43 & 0 & 46 & 0 & 0 & 0 & 0 & 0 & 0 & 0 & 75 & 43 & 73 & 100 & \text { NT } & 50 & 0 & 0\end{array}$ $\begin{array}{llllllllllllllllllllll}100 & 100 & 100 & 100 & 86 & \text { NT } & 91 & 100 & 100 & 100 & 100 & \text { NT } & 100 & \text { NT } & 33 & 95 & 89 & 100 & \text { NT } & 50 & \text { NT } & 67\end{array}$ $\begin{array}{llllllllllllllllllllll}33 & 100 & 50 & 20 & 86 & 0 & 73 & 100 & 100 & 92 & 100 & 40 & 0 & 100 & 100 & 38 & 82 & 0 & \text { NT } & 50 & \text { NT } & 33\end{array}$ $\begin{array}{llllllllllllllllllllll}100 & 100 & 25 & 80 & 71 & 0 & 91 & 0 & 0 & 46 & 0 & 100 & 100 & 0 & 0 & 52 & 64 & 100 & \text { NT } & 50 & 0 & 100\end{array}$ $\begin{array}{llllllllllllllllllllll}33 & 100 & 0 & 60 & 57 & 0 & 46 & 0 & 0 & 54 & 0 & 40 & 0 & 0 & 100 & 100 & 100 & 100 & \text { NT } & 100 & 0 & 33\end{array}$ $\begin{array}{rrrrrrrrrrrrrrrrrrrrrr}0 & 0 & 0 & 60 & 57 & 0 & 46 & 0 & 0 & 15 & 0 & 0 & 0 & 0 & 0 & 0 & 0 & 100 & \text { NT } & 0 & 0 & 0\end{array}$ $\begin{array}{lllrrrrrrrrrrrrrrrrrrr}0 & 0 & 0 & 0 & 0 & 0 & 0 & 0 & 0 & 8 & 0 & 0 & 0 & 0 & 0 & 0 & 0 & 0 & \text { NT } & 0 & 100 & 0\end{array}$ $\begin{array}{llllllllllllllllllllll}0 & 0 & 0 & 0 & 0 & 0 & 0 & 0 & 0 & 0 & 0 & 0 & 0 & 0 & 0 & 10 & 0 & 0 & \text { NT } & 33 & 0 & 0\end{array}$ $\begin{array}{llllllllllllllllllllll}\text { NT } & \text { NT } & \text { NT } & \text { NT } & \text { NT } & \text { NT } & \text { NT } & \text { NT } & \text { NT } & \text { NT } & \text { NT } & 0 & \text { NT } & \text { NT } & 25 & 20 & 0 & 0 & \text { NT } & 0 & 0 & \text { NT }\end{array}$

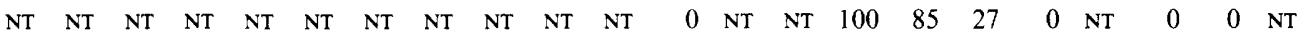
$\begin{array}{llllllllllllllllllllll}0 & 0 & 25 & 20 & 28 & 100 & 0 & 0 & 0 & 31 & 0 & 0 & 0 & 50 & 0 & 0 & 46 & 0 & \text { NT } & 0 & 0 & 67\end{array}$ $\begin{array}{llllllllllllllllllllll}0 & 0 & 50 & 60 & 57 & 100 & 0 & 0 & 0 & 62 & 0 & 0 & 100 & 50 & 0 & 5 & 64 & 0 & \text { NT } & 0 & 25 & 67\end{array}$ $\begin{array}{llllllllllllllllllllll}0 & 0 & 0 & 0 & 0 & 0 & 73 & 0 & 0 & 8 & 0 & 0 & 0 & 0 & 0 & 0 & 0 & 0 & \text { NT } & 0 & 0 & 0\end{array}$ $\begin{array}{llllllllllllllllllllll}0 & 0 & 0 & 0 & 0 & 0 & 73 & 0 & 0 & 8 & 0 & 0 & 0 & 0 & 0 & 0 & 0 & 0 & \text { NT } & 0 & 0 & 0\end{array}$

$\begin{array}{rrrrrrrrrrrrrrrrrrrrrr}0 & 0 & 0 & 0 & 0 & 0 & 0 & 0 & 0 & 0 & 0 & 0 & 0 & 0 & 0 & 38 & 82 & 0 & 0 & 0 & 0 & 0 \\ 0 & 0 & 0 & 0 & 0 & 0 & 0 & 0 & 0 & 0 & 0 & 0 & 0 & 0 & 100 & 100 & 100 & 100 & \text { NT } & 67 & 25 & 0 \\ 0 & 0 & 25 & 0 & 0 & 0 & 0 & 0 & 0 & 8 & 0 & 0 & 0 & 100 & 100 & 100 & 100 & 100 & \text { NT } & 100 & 100 & 0 \\ 0 & 0 & 0 & 0 & 0 & 0 & 0 & 0 & 0 & 8 & 0 & 0 & 0 & 0 & 0 & 10 & 9 & 0 & 0 & 0 & 0 & 0 \\ 0 & \text { NT } & 0 & 0 & 0 & 0 & 0 & 0 & 0 & 0 & 0 & 0 & 0 & 0 & 0 & 40 & 0 & 0 & 0 & 33 & 0 & 0 \\ 0 & \text { NT } & 0 & 0 & 0 & 0 & 0 & 0 & 0 & 0 & 0 & 0 & 0 & 0 & 0 & 4 & 0 & 0 & 0 & 33 & 0 & 0\end{array}$

\begin{tabular}{|c|c|c|c|c|c|c|c|c|c|c|c|c|c|c|c|c|c|c|c|c|c|}
\hline 0 & 0 & 25 & 40 & 57 & 100 & 64 & 0 & 0 & 92 & 0 & 100 & 0 & 100 & 50 & 100 & 100 & 100 & NT & 100 & 100 & 100 \\
\hline 0 & 0 & 0 & 20 & 0 & 0 & 0 & 0 & 0 & 23 & 0 & 100 & . & 100 & 50 & 95 & 91 & 100 & NT & 67 & 100 & , \\
\hline 0 & 0 & 0 & 0 & 0 & 0 & 0 & 0 & 0 & 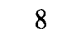 & 0 & 0 & & 100 & 50 & 95 & 27 & 100 & 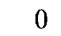 & 67 & 100 & \\
\hline 0 & 0 & 0 & 0 & 0 & 0 & 0 & 0 & 0 & 0 & 0 & 0 & & 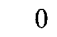 & 25 & 95 & 18 & 100 & 0 & 100 & 100 & \\
\hline 0 & 0 & 0 & 0 & 0 & 0 & 0 & 0 & 0 & 0 & 0 & 0 & & 0 & 0 & 33 & 10 & 100 & 0 & 100 & 100 & \\
\hline 0 & 0 & 0 & 0 & 0 & 0 & 0 & 0 & 8 & 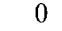 & 0 & 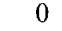 & 0 & 0 & 25 & 0 & 9 & 100 & 0 & 67 & 100 & \\
\hline 33 & 0 & 100 & 80 & 43 & 100 & 100 & 100 & 100 & 100 & 100 & 100 & 100 & 100 & 100 & 100 & 100 & 100 & 100 & 67 & 100 & \\
\hline 0 & 0 & 0 & 0 & 0 & 0 & 73 & 0 & 100 & 85 & 100 & 100 & 0 & 100 & 100 & 100 & 100 & 100 & 100 & 67 & 100 & \\
\hline 0 & 0 & 0 & 0 & 0 & 0 & 0 & 0 & 0 & 46 & 0 & 80 & 0 & 100 & 0 & 57 & 55 & NT & 0 & 67 & 25 & 77 \\
\hline 0 & 0 & 0 & 0 & 0 & 0 & 27 & 0 & 0 & 46 & 0 & 100 & 0 & 0 & 100 & 100 & 100 & NT & 100 & 33 & & \\
\hline 0 & 0 & 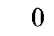 & 0 & 0 & 100 & 80 & 0 & 0 & 100 & 0 & 100 & 100 & 100 & 50 & 100 & 100 & 100 & 100 & 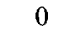 & 25 & \\
\hline 0 & 0 & 75 & 60 & 0 & 100 & 73 & 100 & 100 & 92 & 100 & 100 & 100 & 100 & 75 & 100 & 100 & NT & 0 & 33 & 25 & \\
\hline 67 & 0 & 75 & 100 & 100 & 100 & 91 & 100 & 100 & 100 & 100 & 100 & 100 & 100 & 100 & 33 & 100 & NT & 90 & 100 & 50 & 3 \\
\hline 67 & 100 & 25 & 40 & 0 & 0 & 55 & 100 & 100 & $100^{\circ}$ & 100 & 100 & 100 & 100 & 100 & 100 & 100 & 100 & 100 & 100 & 25 & \\
\hline 0 & 0 & 0 & 0 & 0 & 0 & 0 & 0 & 0 & 23 & 100 & 100 & 0 & 0 & 100 & 0 & 100 & 100 & 100 & 33 & 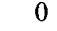 & 33 \\
\hline 0 & 00 & 100 & 100 & 100 & 0 & 91 & 100 & 100 & 92 & 100 & 100 & 100 & 100 & 100 & 100 & 91 & 0 & 100 & 67 & 100 & \\
\hline 0 & 0 & 100 & 80 & 86 & 0 & 36 & 0 & 100 & 77 & 0 & 100 & 0 & 100 & 50 & 52 & 91 & 0 & 100 & 67 & 50 & \\
\hline 0 & 0 & 25 & 20 & 13 & 0 & 0 & 0 & 0 & 8 & 0 & 80 & 0 & 100 & 0 & 38 & 91 & 0 & 0 & 0 & 25 & \\
\hline 0 & 0 & 0 & 0 & 0 & 0 & 0 & 100 & 0 & 46 & 0 & 20 & 0 & 0 & 100 & 100 & 100 & 100 & 100 & 100 & 0 & \\
\hline 0 & 0 & 25 & 0 & 0 & 0 & 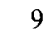 & 0 & 0 & 62 & 100 & 100 & NT & 0 & 100 & 100 & 91 & 100 & 100 & 67 & 0 & \\
\hline 00 & 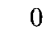 & 75 & 0 & 0 & 0 & 55 & 100 & 100 & 100 & 100 & 100 & 100 & 100 & 100 & 100 & 100 & 100 & 100 & 33 & 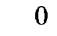 & \\
\hline 0 & 00 & 0 & 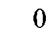 & 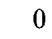 & 0 & 0 & 0 & 0 & 23 & 0 & 0 & 0 & 0 & 0 & 5 & 100 & 100 & 100 & 0 & 8 & \\
\hline 33 & 100 & 25 & ? & 13 & . & 18 & 0 & 0 & 39 & 100 & 100 & 100 & 0 & 75 & 100 & 100 & 100 & 100 & 100 & 25 & \\
\hline
\end{tabular}




\section{Table 3 (continued)}

No. Character

52. Growth on tetrathionate

53. Reduction of tetrathionate

54. Growth on MacConkey agar

55. Growth on deoxycholate-citrate agar

56. Growth on TCBS agar

57. Growth on violet red bile agar

58. Precipitation on violet red bile agar

59. White colonies on $0.01 \%$ tetrazolium, aerobic

60. Red colonies on $0.01 \%$ tetrazolium, aerobic

61. Reduction on $0.01 \%$ tetrazolium, aerobic

62. White colonies on $0.1 \%$ tetrazolium, aerobic

63. Red colonies on $0.1 \%$ tetrazolium, aerobic

64. Reduction on $0.1 \%$ tetrazolium, aerobic

65. White colonies on $0.01 \%$ tetrazolium, anaerobic

66. Red colonies on $0.01 \%$ tetrazolium, anaerobic

67. Reduction on $0.01 \%$ tetrazolium, anaerobic

68. Red colonies on $0.1 \%$ tetrazolium, anaerobic

69. Reduction on $0.1 \%$ tetrazolium, anaerobic

70. Reduction of methylene blue

71. Growth on janus green

72. Reduction of janus green

73. Gas in janus green

74. Acid on BMA

75. Alkali on BMA

Biochemical properties

Constant characters: none were oxidative in Hugh \& Leifson medium

76. Methyl-red positive $35^{\circ} \mathrm{C}$

77. Methyl-red positive $25^{\circ} \mathrm{C}$

78. Vogues-Proskauer $35^{\circ} \mathrm{C}$

79. Voges-Proskauer $25^{\circ} \mathrm{C}$

80. Voges-Proskauer $37^{\circ} \mathrm{C}$ (API)

81. Catalase

82. Oxidase

83. Indole

84. $\mathrm{H}_{2} \mathrm{~S}$ from broth

85. $\mathrm{H}_{2} \mathrm{~S}$ in triple sugar iron agar

86. Nitrate reduction

87. Gas from nitrate

88. Destruction of $0.001 \%$ nitrite

89. Destruction of $0.01 \%$ nitrite

90. Gelatin liquefaction

91. Tributyrin hydrolysis

92. Casein hydrolysis

93. Hydrolysis of Tween 20

94. Hydrolysis of Tween 40

95. Hydrolysis of Tween 60

96. Hydrolysis of Tween 80

97. Tyrosine digestion

98. Urease

99. Urease (API)

100. Phosphatase

101. Lecithinase

102. Deoxyribonuclease

103. Orange fluorescence on DNAase agar

104. Brown fluorescence on DNAase agar

105. Aesculin hydrolysis (API)

106. Arginine dihydrolase

107. Lysine decarboxylase

108. Ornithine decarboxylase

109. Tryptophan deaminase

110. Citrate utilization (Christensen)

111. Citrate utilization (API) $\begin{array}{lllllllllll}\text { Phenon ... } & 1 & 2 & 3 & 4 & 5 & 6 & 7 & 8 & 9 & 10\end{array}$

$\begin{array}{llllllllll}100 & 100 & 100 & 100 & 100 & 100 & 100 & 100 & 75 & 100\end{array}$

$\begin{array}{llllllllll}79 & 92 & 0 & 100 & 100 & 89 & 100 & 86 & 100 & 100\end{array}$

$\begin{array}{rrrrrrrrrr}100 & 100 & 100 & 67 & 70 & 100 & 96 & 100 & 100 & 100\end{array}$

$\begin{array}{llllllllll}0 & 0 & 0 & 0 & 0 & 0 & 0 & 17 & 0 & 3\end{array}$

$\begin{array}{llllllllll}0 & 0 & 100 & 0 & 0 & 0 & 0 & 0 & 0 & 0\end{array}$

$\begin{array}{llllllllll}100 & 100 & 100 & 100 & \text { NT } & 95 & 96 & 100 & 100 & 28\end{array}$

$\begin{array}{llllllllll}100 & 100 & 0 & 0 & 20 & 89 & 64 & 43 & 0 & 0\end{array}$

$\begin{array}{llllllllll}26 & 50 & \text { NT } & 67 & 0 & 5 & 35 & 13 & 0 & \text { NT }\end{array}$

$\begin{array}{llllllllll}66 & 50 & \text { NT } & 0 & 67 & 95 & 50 & 13 & 13 & 50\end{array}$

$\begin{array}{llllllllll}100 & 100 & \text { NT } & 100 & 100 & 100 & 100 & 100 & 100 & \text { NT }\end{array}$

$\begin{array}{llllllllll}0 & \text { NT } & \text { NT } & 67 & \text { NT } & \text { NT } & \text { NT } & \text { NT } & \text { NT } & \text { NT }\end{array}$

$\begin{array}{llllllllll}0 & \text { NT } & \text { NT } & 0 & \text { NT } & \text { NT } & \text { NT } & \text { NT } & \text { NT } & \text { NT }\end{array}$

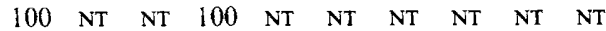

$\begin{array}{llllllllll}0 & 0 & 0 & 0 & 0 & 0 & 0 & 0 & 0 & 0\end{array}$

$\begin{array}{llllllllll}100 & 92 & 100 & 33 & 100 & 84 & 57 & 71 & 100 & 100\end{array}$

$\begin{array}{llllllllll}100 & 100 & 100 & 100 & 100 & 100 & 100 & 100 & 100 & 100\end{array}$

$\begin{array}{llllllllll}40 & 0 & \text { NT } & \text { NT } & 100 & \text { NT } & 39 & \text { NT } & \text { NT } & \text { NT }\end{array}$

$\begin{array}{rrrrrrrrrr}100 & 100 & \text { NT } & 100 & 100 & 100 & 100 & 89 & \text { NT } & 100\end{array}$

$\begin{array}{llllllllll}32 & 39 & 100 & 67 & 50 & 63 & 75 & 28 & 13 & 20\end{array}$

$\begin{array}{rrrrrrrrrr}100 & 100 & 100 & 100 & 100 & 100 & 100 & 100 & 100 & 100\end{array}$

$\begin{array}{llllllllll}0 & 0 & 0 & 0 & 0 & 0 & 0 & 0 & 0 & 0\end{array}$

$\begin{array}{llllllllll}3 & 0 & 0 & 0 & 0 & 0 & 0 & 0 & 0 & 0\end{array}$

$\begin{array}{rrrrrrrrrr}92 & 77 & 0 & 100 & 44 & 89 & 71 & 71 & 38 & 11 \\ 0 & 0 & 0 & 0 & 22 & 0 & 0 & 13 & 0 & 23\end{array}$

$\begin{array}{rrrrrrrrrr}34 & 69 & 100 & 100 & 80 & 36 & 0 & 43 & 13 & 86 \\ 34 & 69 & 0 & 100 & 70 & 68 & 4 & 13 & 0 & 54 \\ 8 & 39 & 0 & 0 & 50 & 21 & 63 & 100 & 75 & 54 \\ 3 & 8 & 100 & 0 & 0 & 21 & 4 & 13 & 0 & 43 \\ 3 & 8 & 100 & 0 & 0 & 0 & 0 & 43 & 0 & 23 \\ 95 & 46 & 100 & 100 & 89 & 57 & 96 & 86 & 0 & 100 \\ 100 & 100 & 0 & 0 & 100 & 84 & 100 & 86 & 100 & 94 \\ 0 & 0 & 0 & 0 & 0 & 0 & 0 & 28 & 0 & 72 \\ 0 & 0 & 0 & 0 & 40 & 16 & 4 & 0 & 0 & 6 \\ 0 & 0 & 0 & 0 & 0 & 0 & 0 & 0 & 0 & 0 \\ 100 & 100 & 100 & 0 & 100 & 100 & 100 & 100 & 100 & 100 \\ 5 & 8 & 0 & 0 & 0 & 11 & 0 & 0 & 0 & 0 \\ 100 & 100 & 100 & 0 & 89 & 100 & 82 & 100 & 63 & 69 \\ 28 & 62 & 100 & 0 & 89 & 100 & 38 & 86 & 0 & 23 \\ 0 & 0 & 0 & 0 & 0 & 0 & 0 & 0 & 0 & 0 \\ 0 & 0 & 0 & 0 & 0 & 0 & 0 & 0 & 0 & 0 \\ 0 & 0 & 0 & 0 & 0 & 0 & \mathrm{NT} & 0 & 0 & 0 \\ 3 & 0 & 0 & 0 & 0 & 0 & 0 & 0 & 0 & 0 \\ 95 & 92 & \mathrm{NT} & 33 & 0 & 6 & 0 & 0 & 0 & 48 \\ 100 & 92 & 100 & 0 & 0 & 6 & 4 & 0 & 0 & 66 \\ 28 & 0 & 0 & 0 & 0 & 0 & 0 & 0 & 0 & 0 \\ 0 & 0 & 100 & 0 & 0 & 0 & 0 & 0 & 0 & 34 \\ 100 & 92 & 100 & 100 & 100 & 95 & 0 & 56 & 0 & 0 \\ 89 & 62 & 100 & 100 & 89 & 63 & 4 & 43 & 0 & 3 \\ 100 & 100 & 0 & 100 & 100 & 100 & 100 & 100 & 100 & 100 \\ 100 & 62 & 0 & 0 & 0 & 0 & 0 & 0 & 0 & 0 \\ 0 & 0 & 0 & 0 & 0 & 5 & 0 & 0 & 0 & 0 \\ 0 & 0 & 0 & 0 & 100 & 0 & 0 & 0 & 0 & 0 \\ 0 & 0 & 0 & 0 & 0 & 11 & 38 & 71 & 63 & 66 \\ 100 & 0 & 100 & 100 & 30 & 0 & 21 & 0 & 75 & 6 \\ 3 & 0 & 0 & 0 & 0 & 0 & 4 & 0 & 0 & 3 \\ 0 & 8 & 0 & 0 & 0 & 0 & 0 & 0 & 0 & 0 \\ 0 & 0 & 0 & 0 & 89 & 0 & 0 & 43 & 0 & 3 \\ 0 & 0 & 0 & 0 & 0 & 0 & 0 & 0 & 0 & 0 \\ 0 & 0 & 0 & 0 & 0 & 0 & 0 & 0 & 0 & 0 \\ 0 & 8 & 0 & 0 & 10 & 0 & 0 & 13 & 0 & 3\end{array}$


Table 3 (continued)

$\begin{array}{llllllllllllllllllllll}11 & 12 & 13 & 14 & 15 & 16 & 17 & 18 & 19 & 20 & 21 & 22 & 23 & 24 & 25 & 26 & 27 & 28 & 29 & 30 & 31 & 32\end{array}$ $\begin{array}{llllllllllllllllllllllll}100 & 100 & 25 & 60 & 13 & 0 & 100 & 0 & 100 & 100 & 100 & 100 & 100 & 100 & 100 & 100 & 100 & 100 & \text { NT } & 100 & 75 & 33\end{array}$ $\begin{array}{llllllllllllllllllllll}100 & 100 & \text { NT } & \text { NT } & \text { NT } & \text { NT } & 100 & \text { NT } & 100 & 92 & 0 & 60 & 0 & 50 & 0 & 5 & 0 & 0 & \text { NT } & 100 & 100 & \text { NT }\end{array}$ $\begin{array}{llllllllllllllllllllll}33 & 0 & 75 & 0 & 43 & 0 & 82 & 100 & 100 & 100 & 100 & 100 & 100 & 100 & 100 & 100 & 100 & 100 & 100 & 100 & 100 & 0\end{array}$ $\begin{array}{llllllllllllllllllllll}0 & 0 & 0 & 0 & 0 & 0 & 0 & 0 & 0 & 15 & 0 & 20 & 0 & 100 & 100 & 100 & 100 & 100 & 100 & 33 & 0 & 0\end{array}$ $\begin{array}{llllllllllllllllllllll}0 & 100 & 0 & 0 & 0 & 0 & 0 & 0 & 0 & 0 & 0 & 0 & 0 & 0 & 0 & 52 & 0 & 0 & \text { NT } & 0 & 25 & 0\end{array}$ $\begin{array}{rrrrrrrrrrrrrrrrrrrrrrrr}0 & 0 & 75 & 0 & 0 & 0 & 82 & 0 & 0 & 100 & 100 & 100 & 0 & 100 & 100 & 100 & 100 & 100 & 100 & 67 & 0 & 0\end{array}$ $\begin{array}{llllllllllllllllllllll}\text { NT } & \text { NT } & 0 & \text { NT } & \text { NT } & \text { NT } & 89 & \text { NT } & \text { NT } & 77 & 100 & 80 & \text { NT } & 100 & 0 & 10 & 0 & 0 & 0 & 0 & 0 & \text { NT }\end{array}$ $\begin{array}{llllllllllllllllllllll}0 & \text { NT } & \text { NT } & \text { NT } & \text { NT } & \text { NT } & 25 & \text { NT } & 0 & 0 & 0 & 0 & 0 & 100 & 25 & 95 & 100 & 100 & 100 & 0 & 0 & 0\end{array}$

$\begin{array}{llllllllllllllllllllll}0 & \text { NT } & \text { NT } & \text { NT } & \text { NT } & \text { NT } & 63 & \text { NT } & 100 & 92 & 100 & 80 & 0 & 0 & 75 & 5 & 0 & 0 & 0 & 100 & 100 & 100\end{array}$

$\begin{array}{llllllllllllllllllllll}0 & \text { NT } & \text { NT } & \text { NT } & \text { NT } & \text { NT } & 100 & \text { NT } & 100 & 100 & 100 & 100 & 100 & 100 & 100 & 24 & 0 & 0 & 0 & 100 & 100 & 100\end{array}$ $\begin{array}{llllllllllllllllllllll}\text { NT } & \text { NT } & \text { NT } & \text { NT } & \text { NT } & \text { NT } & \text { NT } & \text { NT } & \text { NT } & \text { NT } & \text { NT } & 0 & \text { NT } & \text { NT } & 0 & 10 & 64 & 0 & 100 & 0 & \text { NT } & \text { NT }\end{array}$ $\begin{array}{llllllllllllllllllllll}\text { NT } & \text { NT } & \text { NT } & \text { NT } & \text { NT } & \text { NT } & \text { NT } & \text { NT } & \text { NT } & \text { NT } & \text { NT } & 100 & \text { NT } & \text { NT } & 100 & 86 & 0 & 0 & 0 & 100 & \text { NT } & \text { NT }\end{array}$ $\begin{array}{llllllllllllllllllllll}\text { NT } & \text { NT } & \text { NT } & \text { NT } & \text { NT } & \text { NT } & \text { NT } & \text { NT } & \text { NT } & \text { NT } & \text { NT } & 100 & \text { NT } & \text { NT } & 100 & 100 & 100 & 0 & 0 & 100 & \text { NT } & \text { NT }\end{array}$ $\begin{array}{llllllllllllllllllllll}0 & 0 & 0 & 0 & 0 & 0 & 0 & 0 & 0 & 0 & 0 & 0 & 0 & 0 & 0 & 43 & 100 & 100 & 100 & 0 & 0 & 0\end{array}$ $\begin{array}{llllllllllllllllllllll}100 & 100 & 100 & 100 & 82 & 100 & 91 & 100 & 100 & 85 & 100 & 100 & 100 & 100 & 100 & 57 & 0 & 0 & 0 & 100 & 67 & 100\end{array}$ $\begin{array}{llllllllllllllllllllll}100 & 100 & 100 & 100 & 100 & 100 & 100 & 100 & 100 & 100 & 100 & 100 & 100 & 100 & 100 & 13 & 0 & 0 & 0 & 100 & 67 & 100\end{array}$ $\begin{array}{llllllllllllllllllllll}\text { NT } & 100 & \text { NT } & \text { NT } & \text { NT } & \text { NT } & \text { NT } & \text { NT } & \text { NT } & 100 & 100 & 100 & \text { NT } & 100 & 100 & 100 & 100 & 100 & 100 & 100 & \text { NT } & \text { NT }\end{array}$ $\begin{array}{llllllllllllllllllllll}\text { NT } & 100 & \text { NT } & \text { NT } & \text { NT } & \text { NT } & \text { NT } & \text { NT } & \text { NT } & 100 & 100 & 100 & \text { NT } & 100 & 100 & 100 & 100 & 100 & 100 & 100 & \text { NT } & \text { NT }\end{array}$ $\begin{array}{llllllllllllllllllllll}0 & 0 & 75 & 0 & 13 & 0 & 64 & 0 & 100 & 39 & 100 & 100 & 0 & 100 & 100 & 95 & 91 & 100 & \text { NT } & 100 & 25 & 0\end{array}$ $\begin{array}{llllllllllllllllllllll}100 & 100 & 100 & 100 & 0 & 0 & 100 & 100 & 100 & 100 & 100 & 100 & 100 & 100 & 100 & 100 & 100 & 100 & \text { NT } & 100 & 75 & 0\end{array}$ $\begin{array}{llllllllllllllllllllll}0 & 0 & 100 & 0 & \text { NT } & \text { NT } & 100 & 100 & 100 & 31 & 100 & 60 & 100 & 0 & 0 & 19 & 0 & 0 & \text { NT } & 0 & 0 & \text { NT }\end{array}$ $\begin{array}{llllllllllllllllllllll}0 & 0 & 0 & 0 & \text { NT } & \text { NT } & 0 & 0 & 0 & 0 & 0 & 60 & 0 & 0 & 0 & 19 & 0 & 0 & \text { NT } & 0 & 0 & \text { NT }\end{array}$ $\begin{array}{llllllllllllllllllllll}67 & \text { NT } & 75 & 25 & 28 & 100 & 67 & 100 & 0 & 8 & 100 & 0 & 100 & 0 & 0 & 62 & 27 & \text { NT } & 0 & 0 & 0 & 0\end{array}$ $\begin{array}{llllrlllllllllllllllll}0 & \text { NT } & 0 & 0 & 0 & 0 & 0 & 0 & 0 & 17 & 0 & 20 & 0 & 50 & 0 & 71 & 46 & \text { NT } & 100 & 100 & 25 & 50\end{array}$

$\begin{array}{lllllllllllllllllllllll}100 & 0 & 100 & 0 & 13 & 0 & 46 & 100 & 100 & 100 & 100 & 100 & 100 & 100 & 100 & 100 & 100 & 100 & 100 & 0 & 0 & 0\end{array}$ $\begin{array}{lllllllllllllllllllllll}100 & 0 & 100 & 20 & 82 & 0 & 9 & 100 & 100 & 92 & 100 & 100 & 100 & 100 & 100 & 95 & 100 & 100 & \text { NT } & 0 & 0 & 0\end{array}$ $\begin{array}{lllllllllllllllllllllll}0 & 0 & 0 & 0 & 13 & 100 & 0 & 0 & 0 & 69 & 0 & 0 & 0 & \text { NT } & 0 & 24 & 0 & 0 & 0 & 0 & 0 & 67\end{array}$ $\begin{array}{llllllllllllllllllllll}0 & 0 & 0 & 0 & 0 & 0 & 0 & 0 & 0 & 39 & 0 & 0 & 100 & 50 & 0 & 80 & 0 & 0 & \text { NT } & 0 & 0 & 0\end{array}$ $\begin{array}{llllllllllllllllllllll}0 & 0 & 25 & 0 & 0 & 0 & 0 & 0 & 0 & 8 & 0 & 20 & \mathrm{NT} & 0 & 50 & 10 & 0 & 0 & 0 & 0 & 0 & 0\end{array}$ $\begin{array}{llllllllllllllllllllll}100 & 100 & 50 & 100 & 57 & 100 & 100 & 100 & 100 & 92 & 0 & 100 & 0 & 100 & 100 & 100 & 100 & 100 & 100 & 67 & 100 & 67\end{array}$ $\begin{array}{llllllllllllllllllllll}\text { NT } & 100 & 0 & 60 & 86 & 100 & 91 & 0 & 100 & 46 & 0 & 100 & 100 & 100 & 50 & 0 & 0 & 0 & 0 & 67 & 100 & 100\end{array}$ $\begin{array}{llllllllllllllllllllll}0 & 0 & 0 & 0 & 0 & 0 & 0 & 100 & 100 & 39 & 0 & 0 & \mathrm{NT} & 0 & 0 & 24 & 0 & 0 & 0 & 0 & 0 & 0\end{array}$ $\begin{array}{llllllllllllllllllllll}0 & 0 & 0 & 0 & 0 & 100 & 0 & 0 & 0 & 77 & 0 & 80 & 100 & 100 & 0 & 0 & 0 & 0 & \text { NT } & 0 & 25 & 0\end{array}$ $\begin{array}{llllllllllllllllllllll}0 & 0 & 0 & 0 & 0 & 0 & 64 & 0 & 0 & 0 & 0 & 0 & 0 & 0 & 0 & 0 & 0 & 0 & \text { NT } & 0 & 100 & 0\end{array}$ $\begin{array}{llllllllllllllllllllll}100 & \text { NT } & 100 & 100 & 100 & 100 & 91 & 100 & 100 & 100 & 100 & 100 & 100 & 100 & 25 & 100 & 100 & 100 & 100 & 67 & 0 & 0\end{array}$ $\begin{array}{llllllllllllllllllllll}0 & \text { NT } & 0 & 0 & 13 & 0 & 0 & 0 & 0 & 15 & 0 & 80 & 0 & 0 & 0 & 0 & 0 & 0 & 0 & 0 & 0 & 0\end{array}$ $\begin{array}{llllllllllllllllllllll}67 & 0 & 75 & 50 & 100 & 0 & 100 & 100 & 100 & 100 & 100 & 100 & 100 & 100 & 100 & 100 & 36 & 0 & 0 & 0 & 0 & 100\end{array}$ $\begin{array}{llllllllllllllllllllll}0 & 0 & 75 & 0 & 0 & 0 & 73 & 100 & 100 & 77 & 100 & 100 & 0 & 0 & 100 & 95 & 0 & 0 & 0 & 0 & 0 & 0\end{array}$ $\begin{array}{llllllllllllllllllllll}0 & 0 & 0 & 0 & 0 & 0 & 0 & 0 & 0 & 0 & 0 & 0 & 0 & 0 & 0 & 0 & 0 & 0 & 0 & 0 & 100 & 0\end{array}$ $\begin{array}{lllllllllllllllllllllll}0 & \mathrm{NT} & 0 & 0 & 0 & 0 & 0 & 0 & 0 & 0 & 0 & 0 & 0 & 0 & 0 & 100 & 0 & \mathrm{NT} & 0 & 0 & \mathrm{NT} & \mathrm{NT}\end{array}$ $\begin{array}{llllllllllllllllllllll}\text { NT } & \text { NT } & \text { NT } & \text { NT } & \text { NT } & \text { NT } & 0 & \text { NT } & \text { NT } & 0 & 0 & 20 & \text { NT } & 0 & 0 & 0 & 0 & 0 & 0 & 0 & 0 & \text { NT }\end{array}$ $\begin{array}{llllllllllllllllllllll}\text { NT } & 100 & 0 & 0 & 13 & 0 & 0 & 0 & 0 & 0 & 0 & 0 & 0 & 0 & 0 & 5 & 55 & 0 & 0 & 0 & 100 & 100\end{array}$

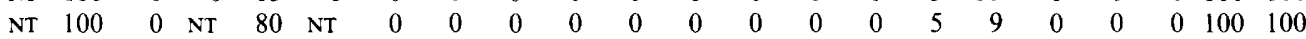

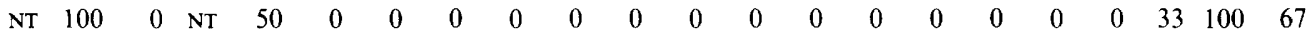
$\begin{array}{llllllllllllllllllllll}0 & \mathrm{NT} & 0 & 0 & 0 & 0 & 0 & 0 & 0 & 0 & 0 & 0 & 0 & 0 & 0 & 0 & 9 & 0 & 0 & 0 & 100 & 0\end{array}$ $\begin{array}{llllllllllllllllllllll}0 & 0 & 0 & 0 & 0 & 0 & 0 & 0 & 0 & 0 & 0 & 0 & 0 & 0 & 0 & 0 & 0 & \text { NT } & 0 & 0 & 0 & 0\end{array}$ $\begin{array}{llllllllllllllllllllll}0 & 100 & 0 & 0 & 100 & 100 & 100 & 100 & 100 & 92 & 100 & 100 & 0 & 0 & 100 & 100 & 100 & 100 & 0 & 100 & 0 & 67\end{array}$ $\begin{array}{llllllllllllllllllllll}0 & 0 & 0 & 0 & 13 & 0 & 55 & 100 & 0 & 54 & 0 & 0 & 0 & 0 & 100 & 100 & 91 & 100 & 0 & 33 & 0 & 67\end{array}$ $\begin{array}{llllllllllllllllllllll}100 & 100 & 100 & 0 & 100 & 100 & 100 & 0 & 100 & 92 & 0 & 100 & 100 & 100 & 0 & 10 & 18 & 0 & 0 & 33 & 100 & 100\end{array}$

$\begin{array}{rrrrrrrrrrrrrrrrrrrrrr}0 & 0 & 0 & 0 & 0 & 0 & 36 & 0 & 0 & 0 & 0 & 0 & 0 & 0 & 0 & 0 & 0 & \text { NT } & 0 & 0 & 25 & 33 \\ 0 & 0 & 0 & 0 & 0 & 0 & 0 & 0 & 0 & 0 & 0 & 0 & 0 & 0 & 0 & 0 & 0 & 0 & 0 & 0 & 0 & 100 \\ 0 & 0 & 0 & 0 & 0 & 0 & 0 & 0 & 0 & 0 & 0 & 0 & 0 & 0 & 0 & 0 & 0 & 0 & 0 & 0 & 0 & 0 \\ 0 & 100 & 0 & 0 & 0 & 0 & 0 & 0 & 0 & 46 & 0 & 0 & 0 & 0 & 0 & 0 & 18 & 100 & 100 & 0 & 0 & 67 \\ 0 & 0 & 0 & 40 & 0 & 0 & 64 & 0 & 0 & 8 & 0 & 0 & 0 & 100 & 0 & 10 & 100 & 100 & 100 & 33 & 0 & 0 \\ 0 & 0 & 0 & 0 & 0 & 0 & 0 & 0 & 0 & 0 & 0 & 0 & 0 & 0 & 0 & 0 & 0 & 0 & 0 & 0 & 0 & 0 \\ 0 & 0 & 0 & 0 & 0 & 0 & 0 & 0 & 0 & 0 & 0 & 0 & 0 & 0 & 0 & 0 & 0 & 0 & 0 & 0 & 0 & 0 \\ 0 & 0 & 0 & 40 & 0 & 0 & 0 & 0 & 0 & 23 & 100 & 0 & 0 & 0 & 50 & 100 & 0 & 0 & 0 & 0 & 0 & 0 \\ 0 & 0 & 0 & 0 & 0 & 0 & 0 & 0 & 0 & 0 & 0 & 0 & \text { NT } & 0 & 0 & 0 & 0 & 0 & 0 & 33 & 0 & 0 \\ 0 & 0 & 0 & 0 & 0 & 0 & 0 & 0 & 0 & 0 & 0 & 0 & 0 & 0 & 50 & 24 & 0 & 0 & 0 & 0 & 0 & 0 \\ 0 & 0 & 0 & 0 & 0 & 0 & 0 & 0 & 0 & 0 & 0 & 0 & 0 & 0 & 0 & 5 & 0 & 0 & 0 & 67 & 0 & 33\end{array}$


Table 3 (continued)

No. Character

112. ONPG

113. Levan production

114. Acid on $5 \%$ sucrose agar

115. Gas from glucose broth

116. Gas in Hugh \& Leifson medium

117. Fermentative reaction, Hugh \& Leifson medium

118. Alkalinity, Hugh \& Leifson medium

119. Decolorization, Hugh \& Leifson medium

Acid from carbohydrates, etc.

Constant characters: all strains were negative with amylose and methyl-D-xyloside

120. Adonitol

121. Amygdalin

122. $\mathrm{D}(-)$-Arabinose

123. $\mathrm{L}(+)$-Arabinose

124. Arbutin

125. $\mathrm{D}(+)$-Cellobiose

126. Dextrin

127. Dulcitol

128. Erythritol

129. $\mathrm{D}(-)$-Fructose

130. Galactose

131. Glucose

132. Glycerol

133. Glycogen

134. meso-Inositol

135. Inulin

136. Lactose

137. Maltose

138. Mannitol

139. $\mathrm{D}(+)$-Mannose

140. $\mathrm{D}(+)$-Melezitose

141. $\mathrm{D}(+)$-Melibiose

142. Methyl D-glucoside

143. Methyl D-mannoside

144. $N$-Acetylglucosamine

145. $\mathrm{D}(+)$-Raffinose

146. Rhamnose

147. Ribose

148. Salicin

149. Sorbitol

150. L( -)-Sorbose

151. Starch

152. Sucrose

153. $\mathrm{D}(-)$ Trehalose

154. $\mathrm{D}(+)$ Xylose

155. L ( - Xylose

\begin{tabular}{rrrrrrrrrrr} 
Phenon ... & 1 & 2 & 3 & 4 & 5 & 6 & 7 & 8 & 9 & 10 \\
& 87 & 69 & 100 & 0 & 30 & 79 & 57 & 43 & 0 & 0 \\
& 0 & 8 & 0 & 0 & 0 & 0 & 4 & 0 & 63 & 0 \\
& 100 & 100 & 100 & 0 & 100 & 100 & 100 & 100 & 100 & 97 \\
\multirow{3}{*}{ medium } & 0 & 0 & 0 & 0 & 0 & 0 & 0 & 0 & NT & 0 \\
& 0 & 0 & 0 & 0 & 10 & 0 & 0 & 0 & 0 & 0 \\
& 100 & 100 & 100 & 100 & 100 & 100 & 100 & 100 & 13 & 100 \\
& 0 & 0 & 0 & 0 & 0 & 0 & 0 & 0 & 0 & 0 \\
& 0 & 0 & 0 & 0 & 10 & 0 & 0 & 0 & 0 & 0
\end{tabular}

$\begin{array}{llllllllll}0 & 0 & 0 & 0 & 0 & 0 & 0 & 0 & 0 & 0\end{array}$

$\begin{array}{rrrrrrrrrr}32 & 0 & 100 & 0 & 0 & 0 & 17 & 0 & 25 & 3\end{array}$

$\begin{array}{llllllllll}61 & 15 & 0 & 0 & 30 & 42 & 57 & 86 & 0 & 36\end{array}$

$\begin{array}{rrrrrrrrrr}87 & 8 & 100 & 100 & 100 & 0 & \text { NT } & 28 & 0 & 23\end{array}$

$\begin{array}{llllllllll}97 & 0 & 100 & 100 & 0 & 0 & 13 & 0 & 63 & 3\end{array}$

$\begin{array}{llllllllll}95 & 0 & 100 & 0 & 0 & 0 & 17 & 0 & 25 & 6\end{array}$

$\begin{array}{llllllllll}79 & 23 & 100 & 0 & 0 & 32 & 50 & 28 & 0 & 0\end{array}$

$\begin{array}{llllllllll}0 & 0 & 0 & 0 & 0 & 0 & 0 & 0 & 0 & 9\end{array}$

$\begin{array}{llllllllll}3 & 0 & 0 & 0 & 0 & 0 & 0 & 0 & 0 & 0\end{array}$

$\begin{array}{llllllllll}100 & 100 & 100 & 100 & 100 & 100 & 100 & 100 & 100 & 100\end{array}$

$\begin{array}{llllllllll}82 & 54 & 0 & 100 & 100 & 100 & 92 & 100 & 0 & 94\end{array}$

$\begin{array}{llllllllll}100 & 100 & 100 & 100 & 100 & 100 & 100 & 100 & 100 & 100\end{array}$

$\begin{array}{llllllllll}84 & 85 & 0 & 33 & 30 & 63 & 57 & 86 & 13 & 11\end{array}$

$\begin{array}{llllllllll}5 & 8 & 100 & 0 & 10 & 16 & 0 & 13 & 0 & 0\end{array}$

$\begin{array}{rrrrrrrrrr}0 & 0 & 0 & 0 & 70 & 0 & 71 & 28 & 25 & 0\end{array}$

$\begin{array}{llllllllll}0 & 0 & 0 & 0 & 0 & 0 & 0 & 0 & 0 & 3\end{array}$

$\begin{array}{llllllllll}100 & 100 & 100 & 0 & 20 & 42 & 33 & 28 & 0 & 9\end{array}$

$\begin{array}{llllllllll}97 & 100 & 100 & 67 & 60 & 100 & 100 & 100 & 100 & 20\end{array}$

$\begin{array}{rrrrrrrrrr}5 & 100 & 0 & 100 & 89 & 100 & 100 & 0 & 100 & 86\end{array}$

$\begin{array}{llllllllll}100 & 92 & 100 & 100 & 100 & 100 & 17 & 100 & 100 & 100\end{array}$

$\begin{array}{llllllllll}0 & 0 & 0 & 0 & 10 & 5 & 0 & 0 & 0 & 0\end{array}$

$\begin{array}{rrrrrrrrrr}100 & 92 & 100 & 100 & 0 & 0 & 0 & 28 & 0 & 0\end{array}$

$\begin{array}{rrrrrrrrrr}3 & 0 & 0 & 0 & 0 & 0 & 0 & 13 & 0 & 0 \\ 0 & 0 & 0 & 0 & 0 & 0 & 0 & 0 & 0 & 3\end{array}$

$\begin{array}{rrrrrrrrrr}0 & 0 & 0 & 0 & 0 & 0 & 0 & 0 & 0 & 3 \\ 100 & 92 & 100 & 100 & 100 & 57 & 96 & 100 & 100 & 100\end{array}$

$\begin{array}{llllllllll}100 & 100 & 100 & 0 & 0 & 26 & 46 & 57 & 0 & 3\end{array}$

$\begin{array}{llllllllll}0 & 0 & 0 & 0 & 20 & 0 & 0 & 0 & 0 & 0\end{array}$

$\begin{array}{llllllllll}100 & 100 & 100 & 67 & 89 & 100 & 100 & 100 & 88 & 97\end{array}$

$\begin{array}{llllllllll}100 & 0 & 100 & 67 & 0 & 0 & 17 & 0 & 63 & 9\end{array}$

$\begin{array}{llllllllll}0 & 23 & 0 & 33 & 89 & 16 & 96 & 0 & 100 & 77\end{array}$

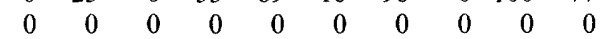

$\begin{array}{rrrrrrrrrr}13 & 0 & 0 & 0 & 0 & 0 & 8 & 0 & 0 & 0\end{array}$

$\begin{array}{llllllllll}100 & 100 & 100 & 33 & 100 & 100 & 96 & 100 & 100 & 97\end{array}$

$\begin{array}{llllllllll}100 & 100 & 100 & 100 & 20 & 0 & 0 & 100 & 100 & 23\end{array}$

$\begin{array}{rrrrrrrrrr}100 & 100 & 100 & 0 & 100 & 100 & 96 & 71 & 0 & 73\end{array}$

$\begin{array}{llllllllll}24 & 0 & 0 & 0 & 10 & 26 & 33 & 43 & 0 & 17\end{array}$

Phenons 18 and 19 are satellites that are indole positive, inositol positive, and give gas in Hugh \& Leifson medium.

Phenon 20 corresponds to Pasteurella aerogenes as it contains the type strain A221, but also strains with other names (see Discussion). Strains grow on violet red bile agar, and with malachite green, crystal violet and $3 \% \mathrm{NaCl}$. They acidify sucrose, galactose and $\mathrm{D}(+)$-xylose. Phenon 21 is a satellite that is unusual in acidifying sorbose and $\mathrm{L}(-)$-xylose.

Phenon 22, referred to as the 'aer-2' groups, is a small group of aerogenic strains quite similar to phenon 20 . It is characteristically positive for dulcitol, starch and rhamnose. Phenon 23 is a satellite notable for acidifying starch, and it is catalase negative. 
Table 3 (continued)

$\begin{array}{rrrrrrrrrrrrrrrrrrrrrr}11 & 12 & 13 & 14 & 15 & 16 & 17 & 18 & 19 & 20 & 21 & 22 & 23 & 24 & 25 & 26 & 27 & 28 & 29 & 30 & 31 & 32 \\ 0 & 0 & 0 & 0 & 0 & 0 & 82 & 0 & 0 & 77 & 0 & 100 & 100 & 100 & 25 & 33 & 100 & 0 & 100 & 33 & 50 & 0 \\ 0 & 0 & 0 & 0 & 13 & 0 & 0 & \text { NT } & \text { NT } & 0 & 0 & 0 & 0 & 0 & 0 & 0 & 0 & 0 & \text { NT } & 0 & 50 & 0 \\ 0 & 0 & 0 & 0 & 100 & 100 & 0 & \text { NT } & \text { NT } & 100 & 100 & 100 & 100 & 100 & 50 & 100 & 0 & 0 & \text { NT } & 0 & 25 & 0 \\ \text { NT } & 0 & 0 & 0 & 0 & 0 & 0 & 0 & 0 & 31 & 0 & 80 & 0 & 0 & 0 & 71 & 0 & 0 & 0 & 0 & 0 & \text { NT } \\ \text { NT } & 0 & 75 & 0 & 0 & 0 & 27 & 100 & 100 & 31 & 0 & 100 & 100 & 0 & 0 & 0 & 0 & 0 & 0 & 0 & 0 & 0 \\ 100 & \text { NT } & 100 & 80 & 100 & 0 & 100 & 100 & 100 & 100 & 100 & 100 & 100 & 100 & 100 & 100 & 100 & 100 & 100 & 0 & 0 & 0 \\ 0 & \mathrm{NT} & 0 & 20 & 0 & 0 & 0 & 0 & 0 & 0 & 0 & 0 & 0 & 0 & 0 & 0 & 0 & 0 & 0 & 100 & 100 & 100 \\ 0 & \mathrm{NT} & 75 & 0 & 0 & 0 & 100 & 100 & 100 & 31 & 100 & 100 & 0 & 0 & 0 & 0 & 0 & 0 & 0 & 0 & 0 & 0\end{array}$

\begin{tabular}{|c|c|c|c|c|c|c|c|c|c|c|c|c|c|c|c|c|c|c|c|c|c|}
\hline 0 & 0 & 0 & 0 & 0 & 0 & 0 & 0 & 0 & 0 & 0 & 0 & 0 & 0 & 0 & 0 & 0 & 0 & 0 & 33 & 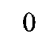 & \\
\hline 0 & 0 & 0 & 0 & 17 & 0 & 0 & 0 & 0 & 0 & 0 & 0 & 0 & 0 & 0 & 0 & 0 & 0 & 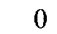 & 0 & & 33 \\
\hline 0 & 0 & 0 & 0 & 0 & 0 & 27 & 100 & 0 & 23 & 100 & 100 & 0 & 100 & 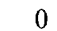 & 43 & 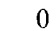 & 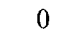 & 100 & & & \\
\hline 0 & 0 & 0 & 0 & 0 & 0 & 100 & 100 & 100 & 62 & 100 & 100 & 100 & 100 & 100 & 100 & 100 & 100 & 100 & 33 & & \\
\hline 0 & 0 & 0 & 0 & 0 & 0 & 9 & 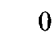 & 0 & 8 & 0 & 0 & 0 & 0 & 50 & 67 & 100 & 100 & 100 & & & \\
\hline 0 & 0 & 0 & 0 & 0 & 0 & 0 & 0 & 0 & 0 & 0 & 0 & 0 & 0 & 100 & 100 & 0 & 0 & & & & \\
\hline 57 & 0 & 0 & 0 & 13 & 0 & 0 & 100 & 0 & 8 & 100 & 100 & 100 & 0 & 0 & 5 & 0 & 0 & 100 & 0 & 25 & \\
\hline 0 & 0 & 0 & 0 & 0 & 0 & 0 & 0 & 0 & 0 & 0 & 100 & 0 & 0 & 0 & 0 & 0 & 0 & 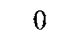 & & & \\
\hline 0 & 0 & 0 & 0 & 0 & 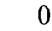 & 0 & 0 & 0 & 0 & 0 & 0 & 0 & 0 & 0 & 5 & 0 & 0 & 100 & & & \\
\hline 00 & 00 & 75 & 80 & 100 & 100 & 100 & 100 & 100 & 100 & 100 & 100 & 100 & 100 & 100 & 100 & 100 & 100 & 100 & c & $\mathcal{J}$ & \\
\hline 0 & 0 & 0 & 0 & 0 & 100 & 91 & 100 & 0 & 100 & 100 & 100 & 100 & 100 & 100 & 100 & 100 & 100 & 100 & 0 & & \\
\hline 00 & 100 & 75 & 20 & 100 & 100 & 91 & 100 & 100 & 100 & 100 & 100 & 100 & 100 & 100 & 100 & 100 & 100 & 100 & & & 33 \\
\hline 0 & 0 & 0 & 0 & 0 & 0 & 82 & 100 & 0 & 46 & 100 & 100 & 100 & 50 & 100 & 100 & 100 & 100 & & & $x$ & \\
\hline 33 & 0 & 0 & 0 & 0 & 8 & 0 & 0 & 0 & 0 & 0 & 20 & 0 & 0 & 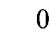 & . & & & & & 50 & \\
\hline 0 & 0 & 0 & 40 & 0 & 0 & 100 & 100 & 100 & 39 & 0 & 0 & 100 & 100 & 50 & 86 & 0 & 0 & 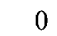 & & & \\
\hline 0 & 0 & 0 & 0 & 0 & 0 & 0 & 0 & 0 & 0 & 0 & 0 & 0 & 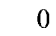 & . & 0 & . & o & ( & & & \\
\hline 0 & 0 & 0 & 0 & 0 & 0 & 36 & 100 & 0 & 15 & 100 & 100 & 100 & 50 & 0 & 10 & 0 & 0 & 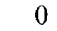 & & 5 & \\
\hline 100 & 100 & 25 & 0 & 86 & 0 & 18 & 100 & 100 & 92 & 100 & 100 & 100 & 100 & 0 & 67 & 100 & 100 & 100 & 0 & 50 & \\
\hline 00 & 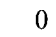 & 0 & 0 & 100 & 0 & 100 & 100 & 100 & 23 & 0 & 0 & 0 & 100 & 100 & 100 & 100 & 100 & 100 & & & \\
\hline 0 & 100 & 75 & 0 & 28 & 100 & 27 & 0 & 0 & 92 & 100 & 100 & 100 & 0 & 100 & 100 & 100 & 100 & 100 & 0 & 7 & \\
\hline 0 & 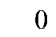 & 0 & 0 & 0 & 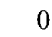 & 0 & 0 & 0 & 0 & 0 & 0 & 0 & 0 & 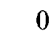 & 0 & 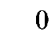 & 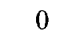 & 0 & & 50 & \\
\hline 0 & 0 & 0 & 0 & 0 & 0 & 0 & 0 & 0 & 39 & 100 & 100 & 100 & 0 & $\mathrm{v}$ & 0 & 82 & ( & ( & & & \\
\hline 0 & 0 & 0 & 0 & 0 & 0 & 0 & 0 & 0 & 0 & 0 & 0 & 0 & 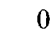 & 0 & 10 & 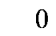 & 0 & ( & ( & 25 & \\
\hline 0 & 0 & 0 & 0 & 0 & 0 & 0 & 0 & 0 & 0 & 0 & 0 & 0 & 0 & 0 & 5 & 0 & 0 & 0 & & & \\
\hline 100 & 0 & 75 & 0 & 71 & 100 & 0 & 0 & 0 & 92 & 0 & 100 & 100 & 100 & 100 & 95 & 100 & 100 & 100 & c & & \\
\hline 0 & 0 & 0 & 0 & 0 & 0 & 18 & 0 & 0 & 46 & 100 & 100 & 100 & 0 & 0 & 0 & 0 & 0 & 0 & ( & & \\
\hline 0 & 0 & 0 & 0 & 0 & 0 & 73 & 0 & 0 & 8 & 100 & 100 & 0 & 0 & 0 & 0 & 100 & 100 & ( & & & \\
\hline 00 & 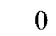 & 50 & 20 & 86 & 100 & 100 & 00 & 00 & 00 & 100 & 100 & 100 & 100 & 100 & 100 & 100 & 100 & 100 & 0 & 75 & \\
\hline 0 & 0 & 0 & 0 & 0 & 0 & 0 & 0 & 0 & 8 & 0 & 0 & 0 & 0 & 0 & 38 & 91 & 100 & 100 & & & \\
\hline 00 & 0 & 0 & 0 & 13 & 0 & 100 & 100 & 100 & 15 & 0 & 0 & 0 & - & 50 & 100 & 0 & 0 & 50 & 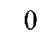 & & \\
\hline 0 & 0 & 0 & 0 & 0 & 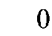 & 0 & 0 & 0 & 0 & 100 & 0 & 0 & 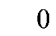 & 50 & 86 & 0 & 0 & ( & & & \\
\hline 0 & 0 & 0 & 0 & 0 & 0 & 0 & 100 & 0 & 0 & 0 & 100 & 100 & 0 & 0 & 0 & 0 & 0 & ( & & & \\
\hline 0 & 0 & 0 & 0 & 100 & 100 & 0 & 100 & 100 & 100 & 100 & 100 & 100 & 100 & 50 & 100 & 9 & 0 & 0 & 0 & 75 & \\
\hline 0 & 0 & 0 & 0 & 0 & 0 & 0 & 0 & 0 & 23 & 100 & 0 & 0 & 0 & 50 & 95 & 100 & 100 & 100 & 0 & 50 & \\
\hline 0 & 0 & 0 & 0 & 0 & 0 & 91 & 100 & 100 & 100 & 100 & 100 & 100 & 100 & 50 & 57 & 91 & 0 & 100 & U & 0 & \\
\hline 0 & 0 & 0 & 0 & 0 & 0 & 9 & 0 & 0 & 8 & 100 & 20 & 0 & 0 & 0 & 0 & 0 & 0 & 10 & 0 & 0 & \\
\hline
\end{tabular}

Phenon 24 contains two replicates of a strain from a tortoise, and is referred to as the 'tortoise' group (see Discussion). These strains grew in $5 \% \mathrm{NaCl}$ and were resistant to azide and arsenate; they grew at $15^{\circ} \mathrm{C}$ and acidified $\mathrm{D}(-)$-arabinose.

Area B: yersinias (phenons 25-29).

Phenons 25 and 26 comprise strains of Yersinia enterocolitica. Although our study did not include the type strain (ATCC 9610), there is little doubt that phenon 26 corresponds to classical $Y$. enterocolitica, and phenon 25 (referred to as the 'ent-b' group) consists of strains that are less typical (see Discussion). These bacteria are characteristically able to grow at $10^{\circ} \mathrm{C}$ and on 
deoxycholate-citrate agar, and with acriflavine and copper sulphate. They acidify cellobiose, but seldom hydrolyse aesculin.

Phenon 27 is Yersinia pseudotuberculosis and phenon 28 appears to be a typical strain of this species. These phenons grow at $10{ }^{\circ} \mathrm{C}$ and on deoxycholate-citrate agar, and with acriflavine and copper sulphate, but also with tellurite. They are aesculin positive.

Phenon 29 (Yersinia pestis) is represented by replicates of only one strain, but it notable for acidifying erythritol and $\mathrm{L}(-)$-xylose. These two test results are, however, not typical of the species (Bercovier \& Mollaret, 1984).

Area $C$ : miscellaneous (phenons 30-32).

These three groups are non-fermentative and produce alkali in Hugh \& Leifson medium. They are the most isolated in the phenogram (Fig. 1).

Phenon 30. This miscellaneous group, referred to here as 'past-b', contains three strains which are not very closely allied to each other or to other phenons (see Discussion). They grow both in $7 \% \mathrm{NaCl}$ and with copper sulphate.

Phenon 31 (Yersinia philomiragia) is characteristically positive for gelatinase and is lipolytic on Tweens. Strains grow on $8 \% \mathrm{NaCl}$ and produce $\mathrm{H}_{2} \mathrm{~S}$ in triple sugar iron medium.

Phenon 32 is Moraxella anatipestifer. Strains are positive for DNAase, sensitive to janus green and to Teepol, but show some lipolysis of Tweens.

\section{Distinctness of phenons and their relationship in phenetic space}

Compactness and overlap of phenons. The phenons vary considerably in compactness (Fig. 1 and $d_{J}$ in Table 2), from $P$. aerogenes, phenon 20 , the least compact, to the most compact, phenon 29 ( $Y$. pestis). The values for some phenons are based on few strains, or are based on replicates, and so they may reflect mainly lack of test reproducibility (e.g. phenons 24 and 29), but it may be noted that $P$. multocida, which has traditionally been considered a rather variable species, is indeed among the less compact. The high variability of phenon 8 is partly accounted for by containing $P$. pneumotropica and $P$. gallinarum which are probably distinct (see Discussion).

The overlap statistics show that the great majority of the phenons are quite distinct. Only six pairs showed a nominal overlap, $V_{G}$, of more than $1 \%$; the phenon pairs $7: 32,8: 10,8: 20$, $10: 11,10: 32$ and $25: 26$. All these showed overlap of less than $5 \%$, except for the last, and the small number of strains prevents a satisfactory test of significance. The last, however, showed about $17.6 \%$ overlap, which is considered in the Discussion.

Principal coordinates analysis. A general view of the major relationships of the phenons is shown in Fig. 2. It should be noted that ordinations such as Fig. 2 do not reflect exactly the same aspects of multidimensional relationships as phenograms, but in this instance, the discrepancies are small. The main groupings of the phenogram are reflected in Fig. 2. Phenons of group A (phenons 1-24) lie mainly at the back and to the left: these represent the actinobacilli and pasteurellae. Phenons of group B (25-29, the yersinias) lie to the front and left. The group C phenons (30-32) lie to the right: these represent the most atypical organisms, and they are joined in Fig. 2 by phenons 12 (a satellite) and 14 ('A. seminis'), which are also very different from most of the other groups.

The variance on the first three axes (indicated by the eigenvalues) is just over $40 \%$, somewhat low for such analyses (Bridge \& Sneath, 1983). The sum of the first eight eigenvalues represents $63.12 \%$ of the total variation. Phenons with high metabolic activity lie to the right in Fig. 2, and those with low activity to the left, as shown by the vigour values (Table 2).

\section{Other findings}

Single Linkage clustering with $S_{G}$. Single Linkage (cophenetic $r=0 \cdot 74$ ) showed similar structure to the UPGMA clustering in Fig. 1. The strain membership of phenons was broadly the same, and indentical in many, but a few strains of some phenons moved out into poorly clustered regions of the phenogram. One such contained a few strains from phenons 2 to 7 . A subcluster of $A$. equuli (A255-258) moved close to $P$. haemolytica biovar A, and A. lignieresii also appeared in two subgroups, not well separated from $A$. equuli and $P$. haemolytica biovar A. The 


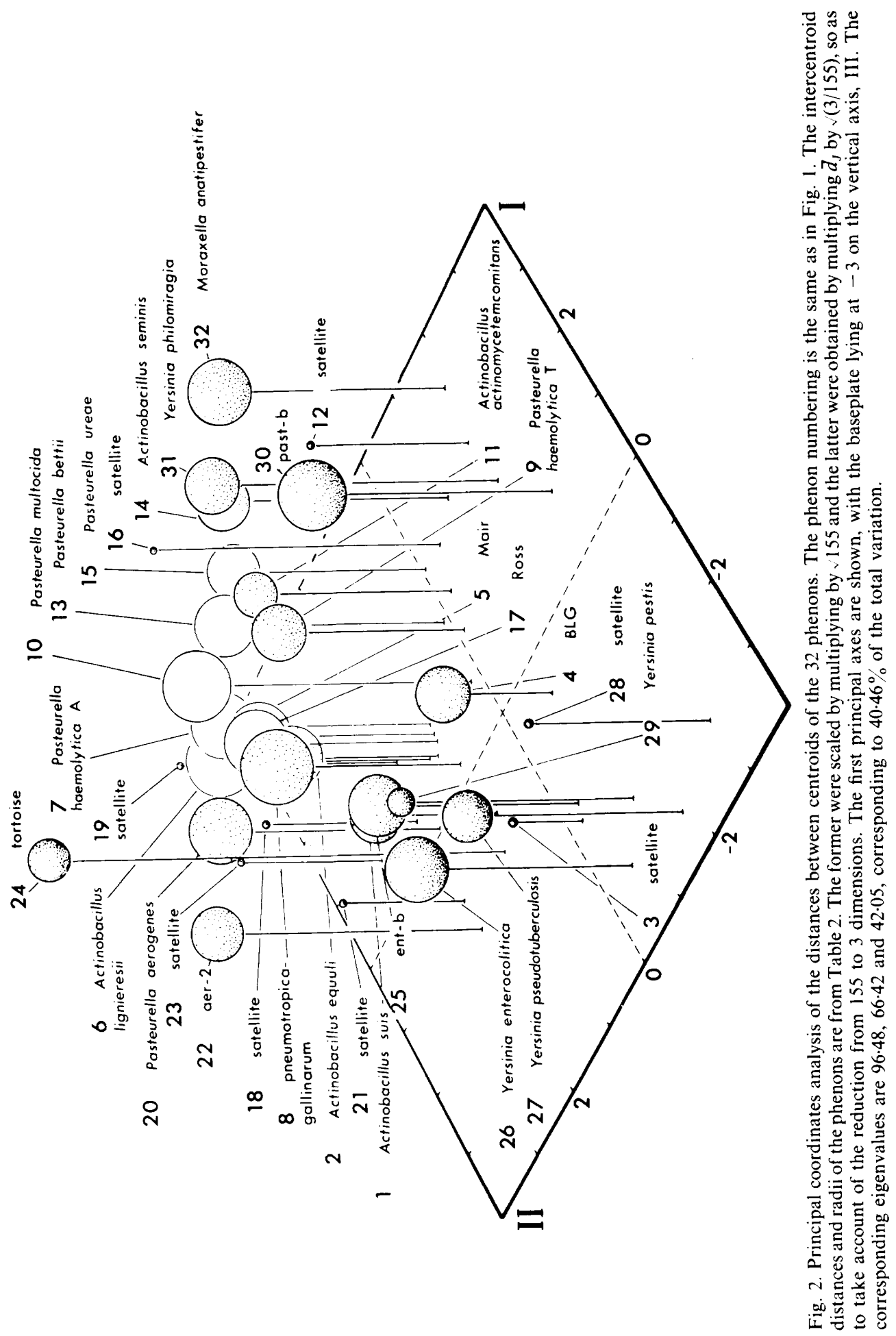


strains of $P$. aerogenes (phenon 20) and of phenon 8 were often mingled and showed poor clustering. The arrangement into the groups A, B and C was, however, broadly preserved.

Vigour and Pattern Coefficients. The vigour of the phenons (which largely reflects metabolic activity) varies a good deal (Table 2 ) from the metabolically inactive 'A. seminis' and Moraxella anatipestifer to the metabolically active yersinias. Among the latter, as expected, phenon 25 contains strains similar to $Y$. enterocolitica but of lower vigour (see Discussion).

There is no marked difference in vigour between the accepted species of Actinobacillus and Pasteurella, although if $A$. actinomycetemcomitans is excluded the actinobacilli show higher values than most of the pasteurellae. P. aerogenes (and also the similar strains in phenon 22) shows high vigour values, however. $P$. haemolytica biovar $\mathrm{T}$ is notably less metabolically active than biovar A. In this respect, the 'BLG' and 'P. bettii' groups are more like classical pasteurellae than classical actinobacilli.

The UPGMA phenogram with the Pattern Coefficient (cophenetic $r=0.81$ ) showed phenons with almost the same members as that with $S_{G}$. The main differences were as follows. The satellite phenon 3 moved near the yersinias. Phenon 8 moved near $P$. multocida, as did $A$. actinomycetemcomitans. $P$. ureae was closer to $A$. equuli. The aerogenic phenons were somewhat rearranged: $P$. aerogenes divided into two, one (including the type strain) was combined with ' $P$. bettii'. The areas A, B and C were preserved except that phenon 4 ('BLG') became attached to the yersinias.

It is usual to find with the Pattern Difference $\left(D_{P}\right)$ that some satellites move into well-defined clusters because they are slow-growing variants whose slower growth leads to differences from typical members of their species, and this is corrected by using the $D_{P}$ coefficient. In this study, however, only the satellite A24l (phenon 16) behaved in this manner; it moved into P. aerogenes, and is presumably a member of that or of a closely related species.

The phenon 'aer-2' (phenon 22) remained a separate group with $D_{P}$, with A163 (phenon 12) as a satellite. A few strains moved in an unexpected way: 'A. seminis' A280 moved into A. suis, and $P$. ureae A87 moved into A. equuli, while A. equuli A264 moved into $P$. ureae. These indicate that the pairs of taxa involved are rather similar in phenotype if the vigour component is removed, i.e. 'A. seminis' has positive properties similar to $A$. suis, and $P$. ureae to $A$. equuli.

The Single Linkage phenogram with $D_{P}$ (cophenetic $r=0.68$ ) was similar to the Single Linkage phenogram with $S_{G}$ and no special points of interest emerge: again the region of $P$. aerogenes, $P$. pneumotropica and $P$. gallinarum was not well-clustered.

Cophenetic discrepancies. Most of the distortion between a similarity matrix and a phenogram derived from it is due to a few of the OTUs (Sneath \& Sokal, 1973; p. 282). As has been found in earlier studies (Sneath et al. 1981; Bridge \& Sneath, 1983), these 'poorly fitting' OTUs are commonly satellite strains or those on the edge of their cluster or from the most peripheral clusters. The highest distortion $\Delta_{j}$ in the $S_{G}$ UPGMA analysis was shown by strains of $M$. anatipestifer. Strains with high $\Delta_{j}$ tended to have vigour values that were either very high or very low. This agrees with the findings of Sneath et al. (1981), though Bridge \& Sneath (1983) found little association between high $\Delta_{j}$ and low vigour.

Identification statistics. The percentages in Table 3 were treated as an identification matrix and evaluated by computer programs. The program MOSTTYP showed that all phenons were readily differentiated by the 155 characters in that identification scores by the most typical possible strain (hypothetical median organism) were always excellent when compared with its own phenon, and much better than the score to the phenon of second choice. The sum of character scores from DIACHAR showed satisfactorily high values for all phenons, ranging from 38.5 for the least well defined, phenon 20 , to 63.5 for the best defined, phenon 21 (excluding higher values for phenons containing only one strain). The properties that were most useful for differentiating the phenons, from CHARSEP, included acid from mannitol, L(+)-arabinose, $\mathrm{D}(-)$-xylose, trehalose, glycerol, sucrose, galactose and sorbitol, and also urease, growth on $1 \%$ Teepol, nitrite destruction, oxidase, ONPG, growth on violet red bile agar and on $3 \% \mathrm{NaCl}$ and hydrolysis of aesculin. The results from OVCLUST were confirmed by the program 
OVERMAT, which showed that all phenons as represented by an identification matrix, were distinct; all possible pairs showed overlap of less than $1 \%$ at the $90 \%$ probability level wherever the numbers of strains allowed significance to be tested. The fact that the nominal overlap of phenons 25 and 26 fell below $1 \%$ presumably reflects the assumption used in the OVERMAT program that the clusters are hyperspherical, which may exaggerate the apparent distinctness between groups.

\section{DISCUSSION}

\section{Test reproducibility}

Replicates on the same batch of medium showed, as expected, rather better test reproducibility than those on different batches, although the difference is not marked. It was unexpected to find better agreement between the same strains from two sources than between deliberate replicates, but in view of the small numbers of strains, this may not be significant. Differences in vigour on the two batches were small. The behaviour of strains of phenon 27 in the two batches of media remains unexplained: there was no difference in the sets of tests, and we presume small changes in test conditions were responsible.

The properties of the phenons agreed reasonably well with those tabulated by Kilian \& Frederiksen (1981), Sakazaki et al. (1981), Carter $(1981,1984)$ and Phillips $(1981,1984)$, if allowance is made for the fact that the carbohydrate fermentations and a few other tests in the API kits were read early, after $24 \mathrm{~h}$ incubation. Also, the conditions in the API kits are not the same in some respects as in conventional tests. Major discrepancies of over $30-40 \%$ are briefly mentioned below, with comments on a few tests where testing conditions are particularly important.

The carbohydrates that were less often acidified in the API kits than expected from the literature (with the relevant phenons in parentheses) included raffinose, melibiose, glycogen and starch (phenons 7 and 9), inositol and salicin (phenon 9), and dextrin (phenons 2, 6, 9 and 20). ONPG was less often hydrolysed than expected (phenons 2, 6, 20 and 26). Cases where acid was produced where none was expected were few : occasional strains acidified sorbitol (phenons 2, 6, 11 and 20), salicin, mannose and cellobiose (phenon 7), mannitol (phenons 1 and 20) and trehalose and raffinose (phenon 20). Weak reactions by phenons 31 and 32 are considered later. We found strains of phenon 4 to acidify galactose and mannose, whereas Jayaraman \& Sethumadavan (1974) found they did not.

In the API galleries the carbohydrate fermentations at $48 \mathrm{~h}$ were usually unchanged from $24 \mathrm{~h}$. The major increases, over $20 \%$, in percentages of positives were as follows: phenon 6 , dextrin rose to $63 \%$; phenon 7 , raffinose rose to $77 \%$; phenon 9 , raffinose rose to $25 \%$; phenon 26, ONPG rose to $65 \%$.

Sticky colonies with pronounced production of mucus were noted for some strains, particularly of phenons $1,2,7,9$ and 31 , and some of these gave the appearance of being capsulated. These findings, however, were often equivocal, and we did not therefore score them as characters.

The ability to grow on MacConkey agar is affected by the batch or formulation. We used Oxoid MacConkey agar with the usual amount of $\mathrm{NaCl}(0.5 \%)$, which contains $0.5 \%(\mathrm{w} / \mathrm{v})$ bile salts, but several formulae are commonly used. This may explain why $P$. multocida, and often $P$. ureae, grew. Similar variability was noted by Sakazaki et al. (1981). It would seem better in future to test resistance to a purified bile salt such as sodium taurocholate or deoxycholate.

Methyl-red and Voges-Proskauer reactions did not always agree with the literature. In our hands, a number of phenons were often positive for both tests at $37^{\circ} \mathrm{C}$, though rarely at $25^{\circ} \mathrm{C}$ or in API kits. These tests, however, are much affected by test conditions, which are often not specified in the literature, and Sakazaki et al. (1981) noted similar variability. There were some discrepancies in indole production: we found that $P$. multocida was sometimes negative and $P$. aerogenes sometimes positive, and $Y$. philomiragia was negative (see Bercovier \& Mollaret, 1984). It is possible that some strains received as $P$. aerogenes are strains of $P$. pneumotropica (which is usually indole positive); the present confusion over these names suggests this should be 
re-investigated. Phenons 6,10 and 17 were seldom positive as expected for $\mathrm{H}_{2} \mathrm{~S}$ (lead acetate paper). We found that $Y$. philomiragia was oxidase positive and $P$. aerogenes was variable.

Destruction of nitrite depends critically on the test conditions. Our results with $0.001 \%$ nitrite agree with the data of Kilian \& Frederiksen (1981) except that most strains of phenon 10 destroyed it, but with the higher level $(0.01 \%)$ fewer phenons were positive. The API urease test was less sensitive than that of Cowan (1974), and strains of phenons 2, 6, 15 and 20 were less often positive in the former.

Major discrepancies were seen in the production of gas from glucose (both in glucose broth and in Hugh \& Leifson medium). However, Kilian \& Frederiksen (1981) incubated for up to $30 \mathrm{~d}$. Nevertheless, the clear clustering of $P$. aerogenes, even though most strains did not produce gas within $2 \mathrm{~d}$, shows that these groups do not turn critically on gas production.

The identification matrix of Bascomb et al. (1973) was not constructed from a numerical taxonomy, so some differences might be expected. We found glycerol was more often acidified than in their matrix, and a few other major percentage discrepancies were found, probably due mainly to the use of API galleries in our study.

The matrix evaluation programs showed that the present 155 characters would allow construction of a reliable computer-assisted identification system. In practice, many tests would be omitted because of the difficulties of making up special media. It would be most convenient to build the system around manufactured kits such as API galleries, but it may be noted that a rich medium like $B M B$ is needed for these bacteria. Useful new tests are suggested by CHARSEP and DIACHAR. These include those based on the following inhibitory compounds (see Methods for concentrations): Teepol, 4,4'-diamidinodiphenylamine, crystal violet, sodium azide, copper sulphate, janus green, malachite green and potassium tellurite. Growth on $3 \%$ $\mathrm{NaCl}$ and violet red bile agar, and lipolysis of Tween 60, may also be useful.

\section{Phenons}

Area $A$ : phenons $1-24$. Strains of $A$. suis (phenon 1) are usually from swine, but also from horses (Biberstein, 1981); three of our strains came from horses. Frederiksen \& Kilian (1981) also mention records from humans. Strains A63 and A64, though received as $A$. lignieresii, are typical $A$. suis and appear to be the $A$. suis strains of Wetmore from irradiated swine referred to by Phillips (1981). We observed slime in stained films less often than expected for this species, and did not note yellow pigment, although this requires special conditions for its observation (Phillips, 1984).

Phenon $2(A$. equuli) is usually associated with septicaemia and joint infections in foals, but may occur in swine (Phillips, 1984), as some of ours did. Phenon 3 remains unidentified. Phenon 4 , the 'BLG group', is distinct, though only a few strains were studied. Our results agreed well with those of Jayaraman \& Sethumadavan (1974) except on galactose and mannose. They were uncertain of the relations to A. lignieresii and $Y$. pseudotuberculosis; there was some evidence of shared antigens with both of these species. These bacteria cause lymphangitis of cattle (Bos indicus) in southern India. It may be noted that phenon 4 in Fig. 2 is close to the yersinias, as it was in the UPGMA phenogram from the Pattern Coefficient. We have not been able to identify phenon 4 with an existing species. Strain A82 was distinctly related to other species in the DNA pairing study of Pohl (1981). Phenon 4 may deserve species status.

Phenon 5 ('Mair' group) is another well-defined group. Its veterinary significance is not clear, though it has been associated with abortion of sows and piglet pneumonia (N. S. Mair, personal communication). Pohl (1981) found that strain A10 was distantly related to A221 (P. aerogenes). This phenon may also deserve species status. A. lignieresii (phenon 6 ) requires little comment. Though found mostly in cattle and sheep, it occurs in the horse (Phillips, 1984), and the equine isolate A58 is a typical strain. However, we subsequently have been told by W. Frederiksen (personal communication) that the organisms from porcine pleuropneumonia of Bertschinger \& Seifert (1978) appear to be strains of $A$. lignieresii, and that their strains are A283, A284, A285 and A286 in this study. They are reported as being similar to Haemophilus pleuropneumoniae but do not require $\mathrm{V}$ factor (Pohl et al., 1983), but in our study they lie unambiguously within phenon 6 . 
Phenons 7 and 9 , the $\mathrm{A}$ and $\mathrm{T}$ biovars of $P$. haemolytica, are clearly very different. The nominal overlap was $6 \times 10^{-4}$, so the phenotypic evidence supports the belief they should be separate species with the epithet haemolytica for biovar A, which contains the type strain. The numerical taxonomy of Sakazaki et al. (1981) and the DNA pairing data of Pohl (1981) are in keeping. Biberstein \& Gills (1962) had noted a sharp separation in the serovars of these strains into the A and T forms, and Biberstein \& Francis (1968) showed they differed on DNA pairing. We found that A104, though received as biovar T, serovar 10, had all the reactions of biovar $\mathrm{A}$. There was no evidence for a subphenon within phenon 7 for the strains bearing the name ' $P$. mastitidis' described by Marsh (1932).

Phenon 8 . We had an inadequate number of strains of this phenon. The type strains of both $P$. pneumotropica and $P$. gallinarum occur in it, and the strains fall into two corresponding subphenons at about $84 \% S_{G}$. More extensive study would probably have shown separate species, in keeping with the findings of Sakazaki et al. (1981) and Pohl (1981). The main differences between the subphenons were as follows: the $P$. pneumotropica subphenon was predominantly urease positive, ONPG positive, dextran negative, resistant to azide and sensitive to borate, whereas the $P$. gallinarum subphenon showed predominantly the opposite reactions. The present data do not clarify the relationships between biovars of $P$. pneumotropica discussed by Frederiksen (1981) and Bisgaard et al. (1983). We did not have a representative of the 'Heyl' biovar, but A80 and A86, belonging respectively to the 'Henriksen/gas' and 'Jawetz' biovars (the latter being the type strain) are both in phenon 8 . There are rather few differences between these biovars, and between them and $P$. gallinarum, but strains of $P$. aerogenes are evidently sometimes misidentified as $P$. pneumotropica (Table 1, phenon 20 ).

$P$. multocida (phenon 10) has in the past been considered a very variable species. Bascomb et al. (1973) separated some strains of $P$. multocida into a separate 'biovar 2' because of the difficulty of identifying them with classical $P$. multocida. We could not identify biovar 2 with any of our phenons, but strains with similar properties occurred in phenons 8,16 and 23 . In this study $P$. multocida is rather diverse but not particularly so (Table 2). In earlier days phenotypically similar forms had not been recognized as distinct species (e.g. $P$. pneumotropica, $P$. aerogenes). The synonym $P$. gallicida has now been suppressed (Judicial Commission of the International Committee on Systematic Bacteriology, 1985).

Pohl (1981) found high DNA pairing between strains that are probably our strains A85, A109, A113 and A114. We did not have a representative of the distinct 'dog-type biovar 6', unless phenon 16 represents this (see below). We found, like Sakazaki et al. (1981), that L-arabinose negative, $D$-xylose positive strains were of avian origin, but the cluster analysis showed no clear subphenons. Representatives of serogroups A to E of Carter (1963) all came in phenon 10.

Phenon 11 strains (A. actinomycetemcomitans) grew rather poorly, which may account for their low vigour (Table 2). This species is common in the human mouth and may be implicated in dental plaque (Frederiksen \& Kilian, 1981). It is distinct in the studies of Sakazaki et al. (1981) and Pohl (1981). Phenon 12 was received as a strain of ' $P$. anatipestifer', but differs in a number of ways, and may have been misidentified. Phenon 13 (' $P$. bettii') is quite distinct. It has been little studied, and might be revived as a species name if more strains could be found. Pohl (1981) placed ' $P$. bettii' near Haemophilus parainfluenzae on DNA pairing. Phenon 14 ('A. seminis') has also been little studied. Pohl (1981) found strain A65 was distant from all of his other species. These strains produced very little acid from carbohydrates and though we thought they were weakly fermentative in Hugh \& Leifson medium, this requires confirmation. ' $A$. seminis' causes epididymitis in rams. One strain received as ' $A$. seminis' (A165) clustered in phenon 30 and is clearly phenotypically different from the strains in phenon 14 . It is noteworthy that Van Tonder (1973) observed that A164 (his strain 6201) and A166 (70-84) were serologically very similar and that A165 (T981V) was serologically different. His serological findings therefore confirm the phenotypic differences. This suggests that further studies might reveal more than one species causing epididymitis in rams.

Phenon 15 is $P$. ureae. We agreed with Kilian \& Frederiksen (1981) that it is usually dulcitol negative, and catalase was difficult to detect in some strains. Henriksen (1961) notes that greening on blood agar may occur at $\mathrm{pH} 6.8$, which may explain the greening we observed. $P$. 
ureae is associated with human respiratory tract infections (Frederiksen \& Kilian, 1981), and is a separate group in the numerical taxonomy of Sakazaki et al. (1981). DNA pairing places it close to $A$. suis and $A$. lignieresii.

Phenon 16 (A241) may represent the 'dog-type' biovar of P. multocida (Kilian \& Frederiksen, 1981), though unlike this type A241 was indole negative and urease positive. Phenon 17, the 'Ross' group, is a well-defined phenon, associated with swine (Ross et al., 1972). Pohl (1981), on DNA pairing, placed it in the neighbourhood of $A$. suis, A. equuli, A. lignieresii and $P$. haemolytica biovar A. Two of our strains were aerogenic on first isolation, and several strains gave gas in Hugh \& Leifson medium. Phenons 18 and 19 are unidentified satellite strains.

Phenon 20 contains both replicates of $P$. aerogenes; other named strains may have been misidentified. Apart from variability in indole and oxidase, our results agree well with the original description of McAllister \& Carter (1974). It has been noted earlier that the low percentage of gas production is probably due to the early time of reading. In agreement with Kilian \& Frederiksen (1981) we found the strains were usually aesculin negative. Phenon 21 may represent an atypical strain of $P$. aerogenes. Phenon 22 ('aer-2'), however, appears to be a distinct gas-producing group, which differs only from descriptions of the 'SP' group (Frederiksen, 1981; Kilian \& Frederiksen, 1981) in being trehalose negative. Like the SP strains, some of them come from guinea pigs. An organism described by Stewart \& Letscher (1976) from guinea pig abscesses is similar. Bisgaard et al. (1983) have described four new taxa from guinea pigs. Of these, taxon 5 and taxon 6 are similar to phenons 20 and 22. Taxon 7 is unlike any other group, whereas taxon 8 is similar to $A$. equuli. Their DNA pairing results were not very conclusive, though Ursing (1981) found that $P$. aerogenes and the SP group were well separated by DNA pairing. Phenon 23 may belong to the $P$. aerogenes complex, because it gave gas in Hugh \& Leifson medium. Phenon 24 (the 'tortoise' group) is not the same as Pasteurella testudinis (see below).

Area B: phenons 25-29. Phenons 25 and 26 contain strains of $Y$. enterocolitica and similar bacteria. Phenon 26 is typical of the species. Phenon 25 resembles $Y$. kristensenii or biovar 5 (Bercovier \& Mollaret, 1984), or the sucrose negative, ornithine decarboxylase negative group A4 forms of Kapperud et al. (1981), which are separate from $Y$. enterocolitica. It was pointed out by Kapperud et al. (1981) that there is an almost continuous gradation from the most metabolically active $Y$. intermedia through $Y$. frederiksenii and $Y$. enterocolitica to $Y$. kristensenii, the least active. This is reflected in the degree of overlap between phenons 25 and 26 (about $17 \%$ as measured by the $V_{G}$ statistic), which is of the order expected from an arbitrary division of a continuous swathe of variation (Sneath, 1977).

Phenons 27 and 28 correspond to Y.pseudotuberculosis. Phenon 28 is a close satellite, and is a replicate of a strain in phenon 27 ; its isolated position is evidently due to lack of test reproducibility. Phenon 29 is $Y$. pestis. This is a very compact phenon because it consists only of a pair of replicates of an avirulent vaccine strain. It does not therefore represent well the diversity of the species. although it does give some indication of phenetic position.

Area $C$ : phenons $30-32$. Phenon 30 is a miscellany of strains. They are not closely similar to one another, and may represent poorly growing pasteurellas (see the low vigour value in Table 2) that are inadequately characterized under the conditions of this survey. Strain A165 has been referred to earlier under phenon 14.

Phenon 31, Y.philomiragia, a pathogen of muskrats but also found in fresh water (Jensen et al., 1969), and phenon 32, Moraxella anatipestifer, which causes septicaemia in ducks (Hendrickson \& Hilbert, 1932) are phenetically very different from the other phenons. Strain A131 of phenon 32 is the most isolated strain in the DNA study of Pohl (1981), and the electropherograms of Harry \& Brown (1981) are very different from those of other pasteurellas. The taxonomic position of both these species is uncertain. Ursing et al. (1980) found no significant DNA pairing between $Y$. philomiragia and other yersinias or with $P$. multocida. $M$. anatipestifer has been regarded as a pasteurella, but present views are that it belongs to neither Pasteurella nor Moraxella (Bøvre, 1984; Carter, 1984). We found that both phenons 31 and 32 gave very weak attack on a few sugars, and no fermentation in $2 \mathrm{~d}$ in Hugh \& Leifson medium. 
Other taxa. We were unable to identify among our strains phenons representing $A$.capsulatus, 'A. hominis' or P. testudinis. A. capsulatus causes joint infections in rabbits (Arseculeratne, 1962). In the description in Kilian \& Frederiksen (1981) A. capsulatus is similar to A. suis, but it is nonhaemolytic and acidifies sorbitol, mannitol and amygdalin. Dr W. Frederiksen kindly sent us strains of $A$. capsulatus and ' $A$. hominis' which we later examined. $A$. capsulatus NCTC 11408 was in our hands very like $A$. suis, but was non-haemolytic and did not acidify $\mathrm{D}(+)$-arabinose; we found it difficult to demonstrate unequivocal capsules.

In the description in Friis-Møller (1981) 'A. hominis' is very similar to $A$. equuli, and differs mainly in being mannose negative and fermenting lactose slowly. Christiansen et al. (1981) found it close on DNA pairing to $A$. equuli and $P$. ureae. We later examined ' $A$. hominis' NCTC 11529, which gave many reactions like those of $A$. equuli, but differed from it in reactions on mannose, glycerol, $\mathrm{D}(+)$-xylose and melibiose.

$P$. testudinis was described by Snipes \& Biberstein (1982) from American desert tortoises. It does not closely resemble phenon 24 , which was from a European tortoise. Dr E. L. Biberstein kindly sent us the type strain of $P$. testudinis (ATCC 33688). Its reactions differed from phenon 24 in $\mathrm{D}(-)$-arabinose, rhamnose, melibiose, raffinose, phosphatase and $\mathrm{H}_{2} \mathrm{~S}$, and it did not correspond to any of our phenons.

We could not identify any of our phenons with the EF-4 group (Holmes \& Ahmed, 1981). Group EF-4 resembles ' $P$. bettii' but is positive for oxidase and gelatinase. 'Pasteurella salpingitidis' of Kohlert (1968) is little known, and does not seem close to other pasteurellas (Pohl, 1981).

\section{Other findings}

The phenons in this study are quite compact considering the amount of test error, because this would itself give $\bar{d}_{J}$ values (Table 2 ) approaching some of those shown. The replicates composing phenons 24 and 29 would, of course, occupy single points if there was complete test reproducibility. There is a remarkable absence of overlap between phenons (except for phenons 25 and 26 as noted above), and the reduction in degrees of freedom because the variables are binary (Bridge \& Sneath, 1983) is not here of practical importance.

The Pattern Coefficient $D_{P}$ has not shown any special features in this study. Two strains moved into different clusters because the correction for vigour was very marked; a strain of ' $A$. seminis' joined $A$. suis, and a strain of $A$. equuli joined $P$. ureae. Such isolated movements have little taxonomic significance, but they do point to pairs of taxa that may be confused if strains grow slowly or tests are read at early times of incubation.

\section{Taxonomic structure of the genera}

The phenotypic relations we found are broadly similar to those of Sakazaki et al. (1981). Those authors found $A$. actinomycetemcomitans to be further from $P$. ureae than is shown by the present study, but they also noted the relatively isolated position of $P$. aerogenes. The DNA-DNA pairing data of Pohl (1981) are also in reasonable agreement with Figs 1 and 2. Both show A. suis close to $A$. equuli and $P$. multocida close to $P$. gallinarum. Pohl (1981) found $P$. ureae was close to $A$. equuli, and $P$. gallinarum was not close to $P$. pneumotropica, but other relations are concordant with his data. Serological relations have been summarized by Carter (1984) and Phillips (1984). There are antigens shared by $A$. lignieresii, A. equuli, $A$. suis and $P$. haemolytica biovar A. The quinone composition of these organisms has been extensively studied by Mannheim and his colleagues, and is summarized by Holländer et al. (1981), but their occurrence is not easy to interpret taxonomically.

The first two main areas $\mathbf{A}$ (actinobacilli and pasteurellas) and $\mathbf{B}$ (yersinias) are separated as expected. Area $\mathrm{C}$ consists of less closely related non-fermenting forms of uncertain affiliation. Mraz (1969) and Sneath \& Johnson (1973) noted that Actinobacillus and Pasteurella are hard to differentiate and this has recently been discussed by Mutters et al. (1984). There are now many more reasons to combine the two genera, and Pasteurella would then be the correct name under the International Code of Nomenclature of Bacteria (Lapage et al., 1975; Rule 24b). Within area $\mathrm{A}$ there is no clear separation of the two genera (Figs 1 and 2). There is also doubt as to 
whether Haemophilus is a separate genus. DNA pairing (Christiansen et al., 1981; Coykendall et al., 1983; Potts \& Berry, 1983) shows fairly high relationships between some species of Haemophilus and Actinobacillus, and Pohl et al. (1983) have transferred Haemophilus pleuropneumoniae to Actinobacillus on DNA evidence (see also Kilian \& Biberstein, 1984).

Mannheim (1984) and Mutters \& Mannheim (1984) have summarized all the DNA evidence. There is a group of species including $P$. multocida, $P$. gallinarum and some strains of $P$. pneumotropica, and perhaps Haemophilus avium. Another group contains $A$. lignieresii, A. equuli, $A$. suis, $A$. capsulatus, the 'Ross group' and $P$. ureae, and probably $H$. pleuropneumoniae. Both biovars of $P$. haemolytica are close to this group. A third group contains $A$. actinomycetemcomitans, and a fourth contains $H$. influenza and $H$. aegyptius. There are also a number of more isolated taxa.

The present study gives a reasonably clear picture of much of the genera Actinobacillus and Pasteurella. There is a good deal of uncertainty, however, about the region containing $P$. pneumotropica, $P$. gallinarum and $P$. aerogenes: a detailed study is needed here. It seems very likely that there are a large number of additional groups to be discovered in these genera (similar to the 'BLG' group, for example); these will probably be restricted to one or two animal hosts. Whether they will deserve species status will depend in large part on the extent to which they can be shown to be distinct and not overlapping. For this reason the use of statistical tests of overlap is highly desirable. If the groups overlap too much, it will be difficult to speciate the genera fully, and a system of biovars may then prove more useful.

This work was supported by project grants from the Medical Research Council. We particularly thank Dr N. S. Mair, Dr W. Frederiksen and Dr E. L. Biberstein for gifts of strains and for helpful advice, and many others who provided strains used in this study. We thank Miss P. A. Pell for technical assistance, and M. J. Sackin for help with computing.

\section{REFERENCES}

ArseculeratNe, S. N. (1962). Actinobacillosis in joints of rabbits. Journal of Comparative Pathology 72, 33-39.

Bascomb, S., Lapage, S. P., Curtis, M. A. \& WillcoX, W. R. (1973). Identification of bacteria by computer: identification of reference strains. Journal of General Microbiology 77, 291-315.

Baynes, I. D. \& Simmons, G. C. (1960). Ovine epididymitis caused by Actinobacillus seminis n. sp. Australian Veterinary Journal 36, 454-459.

Bercovier, H. \& Mollaret, H. H. (1984). Genus XIV Yersinia Van Loghem. In Bergey's Manual of Systematic Bacteriology, vol. 1, pp. 498-506. Edited by N. R. Krieg \& J. G. Holt. Baltimore: Williams \& Wilkins.

Bertschinger, H. U. \& Seifert, F. (1978). Isolation of a Pasteurella haemolytica-like organism from porcine necrotic pleuropneumonia. Proceedings of the 5th IVPS World Congress on Hyology and Hyatrics, Zagreb. Abstract M. 19.

Biberstein, E. L. (1981). Haemophilus-PasteurellaActinobacillus: their significance in veterinary medicine. In Haemophilus, Pasteurella and Actinobacillus, pp. 61-73. Edited by M. Kilian, W. Frederiksen \& E. L. Biberstein. London: Academic Press.

Biberstein, E. L. \& Francis, C. K. (1968). Nucleic acid homologies between the $\mathrm{A}$ and $\mathrm{T}$ types of Pasteurella haemolytica. Journal of Medical Microbiology 1, 105-108.

Biberstein, E. L. \& Gills, M. G. (1962). The relation of the antigenic types to the $\mathrm{A}$ and $\mathrm{T}$ types of Pasteurella haemolytica. Journal of Comparative Pathology and Therapeutics 72, 316-320.
Bisgaard, M., Mutters, R. \& Mannheim, W. (1983). Characterization of some previously unreported taxa isolated from guinea pigs (Cavia porcellus) and provisionally classed with the 'HPA-group'. In Les Bacilles à Gram Negatif d'Intérêt Médical et en Santé Publique, pp. 227-244. Edited by H. Leclerc. Paris: Institut National de la Santé et de la Recherche Médicale.

Bøvre, K. (1984). Genus II. Moraxella Lwoff. In Bergey's Manual of Systematic Bacteriology, vol. 1, pp. 296-303. Edited by N. R. Krieg \& J. G. Holt. Baltimore: Williams \& Wilkins.

Bridge, P. D. \& SNeath, P. H. A. (1983). Numerical taxonomy of Streptococcus. Journal of General Microbiology 129, 565-597.

Broom, A. K. \& Sneath, P. H. A. (1981). Numerical taxonomy of Haemophilus. Journal of General Microbiology 126, 123-149.

CARTer, G. R. (1963). Proposed modification of the serological classification of Pasteurella multocida. Veterinary Record 75, 1264-1265.

Carter, G. R. (1981). The genus Pasteurella. In The Prokaryotes, vol. 2, pp. 1383-1391. Edited by M. P. Starr, H. Stolp, H. G. Trüper, A. Balows \& H. G. Schlegel. Berlin: Springer-Verlag.

Carter, G. R. (1984). Genus I. Pasteurella Trevisan. In Bergey's Manual of Systematic Bacteriology, vol. 1, pp. 552-558. Edited by N. R. Krieg \& J. G. Holt. Baltimore: Williams \& Wilkins.

Christiansen, C., Hansen, E. \& Friss-Møller, A. (1981). Homology between DNA from selected strains of the genera Pasteurella, Actinobacillus and Haemophilus. In Haemophilus, Pasteurella and Actino- 
bacillus, pp. 158-160. Edited by M. Kilian, W. Frederiksen \& E. L. Biberstein. London: Academic Press.

Cowan, S. T. (1974). Cowan \& Steel's Manual for the Identification of Medical Bacteria, 2nd edn. Cambridge: Cambridge University Press.

Coykendall, A. L., Setterfield, J. \& Slots, J. (1983). Deoxyribonucleic acid relatedness among Actinobacillus actinomycetemcomitans, Haemophilus aphrophilus, and other Actinobacillus species. International Journal of Systematic Bacteriology 33, 422-424.

Cutlip, R. C., Amtower, W. C. \& Zinober, M. R. (1972). Septic embolic actinobacillosis of swine: a case report and laboratory reproduction of the disease. American Journal of Veterinary' Research 33, 1621-1626.

Feltham, R. K. A., Power, A. K., Pell, P. A. \& SNEATH, P. H. A. (1978). A simple method for storage of bacteria at $-76^{\circ} \mathrm{C}$. Journal of Applied Bacteriology 44, 313-316.

Frederiksen, W. (1981). Gas producing species within Pasteurella and Actinobacillus. In Haemophilus, Pasteurella and Actinobacillus, pp. 185-196. Edited by M. Kilian, W. Frederikson \& E. L. Biberstein. London: Academic Press.

Frederiksen, W. \& Kilian, M. (1981). Haemophilus-Pasteurella-Actinobacillus: their significance in human medicine. In Haemophilus, Pasteurella and Actinobacillus, pp. 39-55. Edited by M. Kilian, W. Frederiksen \& E. L. Biberstein. London: Academic Press.

Friss-Møller, A. (1981). A new actinobacillus species from the human respiratory tract: Actinobacillus hominis nov. sp. In Haemophilus, Pasteurella and Actinobacillus, pp. 151-157. Edited by M. Kilian, W. Frederiksen \& E. L. Biberstein. London: Academic Press.

Gower, J. C. (1966). Some distance properties of latent root and vector methods used in multivariate analysis. Biometrika 53, 325-338.

Harry, E. G. \& Brown, J. R. (1981). Cell protein electrophoresis as a taxonomic aid, with special reference to Pasteurella. In Haemophilus, Pasteurella and Actinobacillus, pp. 213-220. Edited by M. Kilian, W. Frederiksen \& E. L. Biberstein. London: Academic Press.

Hendrickson, J. M. \& Hilbert, K. F. (1932). A new and serious septicaemic disease of ducks with a description of the causative organism, Pfeifferella anatipestifer. Cornell Veterinarian 22, 239-252.

Henriksen, S. D. (1961). Pasteurella haemolytica var. ureae: action on blood agar and serological reactions. Acta pathologica et microbiologica scandinatica 53 , 425-429.

Holländer, R., Hess-Reihse, A. \& Mannheim, A. (1981). Respiratory quinones in Haemophilus, Pasteurella and Actinobacillus: pattern, function and taxonomic evaluation. In Haemophilus, Pasteurella and Actinobacillus, pp. 83-97. Edited by M. Kilian, W. Frederiksen \& E. L. Biberstein. London: Academic Press.

Holmes, B. \& Ahmed, M. S. (1981). Group EF-4: a Pasteurella-like organism. In Haemophilus, Pasteurella and Haemophilus, pp. 161-174. Edited by M. Kilian. W. Frederiksen \& E. L. Biberstein. London: Academic Press.
Hugh, R. \& Leifson, E. (1953). The taxonomic significance of fermentative versus oxidative metabolism of carbohydrates by various Gram-negative bacteria. Journal of Bacteriology 66, 24-26.

Jayaraman, M. S. \& Sethumadavan, V. (1974). The B. L. organism - the causal agent of bovine lymphangitis in Tamil Nadu. Indian Veterinary Journal 51, 347-355.

JeNSEN, W. I., OWen, C. R. \& Jellison, W. J. (1969). Yersinia philomiragia sp. n., a new member of the Pasteurella group of bacteria, naturally pathogenic for the muskrat (Ondatra zibethica). Journal of Bacteriology 100, 1237-1241.

JUDICIAL COMMISSION OF THE INTERNATIONAL COMMITTEE ON SyStematic BaCteriology. Opinion number 58. (1985). Confirmation of the types in the Approved Lists as nomenclatural types including the recognition of Nocardia asteroides (Eppinger 1891) Blanchard 1896 and Pasteurella multocida (Lehmann and Neumann 1899) Rosenbusch and Merchant 1939 as the respective type species of the genera Nocardia and Pasteurella and rejection of the species name Pasteurella gallicida (Burrill 1883) Buchanan 1925. International Journal of Systematic Bacteriology (in the Press).

Kapperud, G., Bergan, T. \& Lassen, J. (1981). Numerical taxonomy of Yersinia enterocolitica and Yersinia enterocolitica-like bacteria. International Journal of Systematic Bacteriology 31, 401-419.

Kilian, M. \& Biberstein, E. L. (1984). Genus II. Haemophilus Winslow, Broadhurst, Buchanan, Krumwiede, Rogers and Smith. In Bergey's Manual of Systematic Bacteriology, vol. 1, pp. 558-569. Edited by N. R. Krieg \& J. G. Holt. Baltimore: Williams \& Wilkins.

KILIAN, M. \& FREDERIKSEN, W. (1981). Identification tables for the Haemophilus-Pasteurella-Actinobacillus group. In Haemopinilus, Pasteurella and Actinobacillus, pp. 281-290. Edited by M. Kilian, W. Frederiksen \& E. L. Biberstein. London: Academic Press.

Kilian, M., Frederiksen, W. \& Biberstein, E. L. (editors) (1981). Haemophilus, Pasteurella and Actinobacillus. London: Academic Press.

KOHLERT, R. (1968). Untersuchungen zür Ätiologie der Eilecterntzündung beim Huhn. Monatsschrift für Veterinaermedizin 23, 392-395.

Kovacs, N. (1956). Identification of Pseudomonas pyocyanea by the oxidase reaction. Nature, London $178,703$.

Lapage, S. P., Sneath, P. H. A., Lessel, E. F., Skerman, V. B. D., Seeliger, H. P. R. \& Clark, W. A. (editors) (1975). International Code of Nomenclature of Bacteria. Washington DC: American Society for Microbiology.

MCAllister, H. A. \& Carter, G. R. (1974). An aerogenic pasteurella-like organism recovered from swine. American Journal of Veterinary Research 35, 917-922.

Mair, N. S., Randall, C. J., Thomas, G. W., Harbourne, J. F., MCCrea, C. T. \& Cowl, K. P. (1974). Actinobacillus suis infections in pigs: a repert of four outbreaks and two sporadic cases. Journal of Comparative Pathology 84, 113-119.

Mannheim, W. (1984). Family III. Pasteurellaceae Pohl. In Bergey's Manual of Systematic Bacteriology, 
vol. 1, pp. 550-552. Edited by N. R. Krieg \& J. G. Holt. Baltimore: Williams \& Wilkins.

MARSH, H. (1932). Mastitis in ewes, caused by an infection with a pasteurella. Journal of the American Veterinary Medical Association 81, 376-382.

Mraz, O. (1969). Vergleichende Studie der Arten Actinobacillus lignieresii und Pasteurella haemolytica. III. Actinobacillus haemolyticus (Newsom und Cross, 1932. comb. nov). Zentralblatt für Bakteriologie, Parasitenkunde, Infektionskrankheiten und Hygiene, (Abteilung I, Originale) 209, 349-364.

Mutters, R. \& Mannheim, W. (1984). Addendum to the genus Pasteurella. In Bergey's Manual of Systematic Bacteriology, vol. 1, pp. 557-558. Edited by N. R. Krieg \& J. G. Holt. Baltimore: Williams \& Wilkins.

Mutters, R., Piechulla, K. \& Mannheim, W. (1984). Phenotypic differentiation of Pasteurella sensu stricto and the Actinobacillus group. European Journal of Clinical Microbiology 3, 225-229.

Phillips, J. E. (1981). The genus Actinobacillus. In The Prokaryotes, vol. 2, pp. 1392-1398. Edited by M. P. Starr, H. Stolp, H. G. Trüper, A. Balows \& H. G. Schlegel. Berlin: Springer-Verlag.

Phillips, J. E. (1984). Genus III. Actinobacillus Brumpt. In Bergey's Manual of Systematic Bacteriology, vol. 1, pp. 570-575. Edited by N. R. Krieg \& J. G. Holt. Baltimore: Williams \& Wilkins.

POHL, S. (1981). DNA relatedness among members of Haemophilus, Pasteurella and Actinobacillus. In Haemophilus, Pasteurella and Actinobacillus, pp. 245253. Edited by M. Kilian, W. Frederiksen \& E. L. Biberstein. London: Academic Press.

Pohl, S., Bertschinger, H. U., Frederiksen, W. \& Mannheim, W. (1983). Transfer of Haemophilus pleuropneumoniae and the Pasteurella haemolyticalike organisms causing porcine necrotic pleuropneumonia to the genus Actinobacillus (Actinobacillus pleuropneumoniae comb. nov.) on the basis of phenotypic and deoxyribonucleic acid relatedness. International Journal of Systematic Bacteriology 33, $510-514$.

Potts, T. V. \& Berry, E. M. (1983). Deoxyribonucleic acid-deoxyribonucleic acid hybridization analysis of Actinobacillus actinomycetemcomitans and Haemophilus aphrophilus. International Journal of Systematic Bacteriology 33, 765-771.

Ross, R. F., Hall, J. E., Orning, A. P. \& Dale, S. E. (1972). Characterization of an Actinobacillus isolated from the sow vagina. International Journal of Systematic Bacteriology 22, 39-46.

Sakazaki, R., Tamura, K., Kuramochi, S. \& Kosako, M. (1981). Numerical classification of Pasteurella and some Actinobacillus. In Haemophilus, Pasteurella and Actinobacillus, pp. 235-243. Edited by M. Kilian, W. Frederiksen \& E. L. Biberstein. London: Academic Press.

Skerman, V. B. D., McGowan, V. \& Sneath, P. H. A. (editors) (1980). Approved lists of bacterial names. International Journal of Systematic Bacteriology $\mathbf{3 0}$, 225-420.

SNEATH, P. H. A. (1974). Test reproducibility in relation to identification. International Journal of Systematic Bacteriology 24, 508-523.
Sneath, P. H. A. (1977). A method for testing the distinctness of clusters: a test of the disjunction of two clusters in Euclidean space as measured by their overlap. International Journal of the Association for Mathematical Geology 9, 123-143.

SNEATH, P. H. A. (1979a). BASIC program for a significance test for two clusters in Euclidean space as measured by their overlap. Computers and Geosciences 5, 143-155.

SNEATH, P. H. A. $(1979 b)$. BASIC program for character separation indices from an identification matrix of percent positive characters. Computers and Geosciences 5, 349-357.

SNEATH, P. H. A. (1980a). BASIC program for the most diagnostic properties of groups from an identification matrix of percent positive characters. Computers and Geosciences 6, 21-26.

SNEATH, P. H. A. $(1980 b)$. BASIC program for determining the best identification scores possible from the most typical examples when compared with an identification matrix of percent positive characters. Computers and Geosciences 6, 27-34.

SNEATH, P. H. A. $(1980 c)$. BASIC program for determining overlap between groups in an identification matrix of percent positive characters. Computers and Geosciences 6, 267-278.

Sneath, P. H. A. \& Johnson, R. (1972). The influence on numerical taxonomic similarities of errors in microbiological tests. Journal of General Microbiology 72, 377-392.

Sneath, P. H. A. \& Johnson, R. (1973). Numerical taxonomy of Haemophilus and related bacteria. International Journal of Systematic Bacteriology 23, $405-418$.

Sneath, P. H. A. \& Sokal, R. R. (1973). Numerical Taxonomy. San Francisco: W. H. Freeman.

Sneath, P. H. A., Stevens, M. \& Sackin, M. J. (1981). Numerical taxonomy of Pseudomonas based on published records of substrate utilization. Antonie van Leeuwenhoek 47, 423-448.

Snipes, K. P. \& Biberstein, E. L. (1982). Pasteurella testudinis sp. nov.: a parasite of desert tortoises (Gopherus agassizi). International Journal of Systematic Bacteriology 32, 201-210.

SteWART, D. D. \& Letscher, R. M. (1976). Isolation of an atypical Pasteurella-like organism from guinea pig abscesses. Laboratory Animal Sciences 26, 482 485 .

URSING, J. (1981). Deoxyribonucleic acid hybridization studies of gas producing pasteurellae. In Haemophilus, Pasteurella and Actinobacillus, pp. 255263. Edited by M. Kilian, W. Frederiksen \& E. L. Biberstein. London: Academic Press.

Ursing, J., Steigerwalt, A. G. \& Brenner, D. J. (1980). Lack of genetic relatedness between Yersinia philomiragia (the 'Philomiragia' bacterium) and Yersinia species. Current Microbiology 4, 231-233.

VAN TONDER, E. M. (1973). Infection of rams with Actinobacillus seminis. Journal of the South African Veterinary Association 44, 235-240. 